Chapman University

Chapman University Digital Commons

$9-1-2021$

Dynamic Resource Allocation with Cost Externality

Hao Zhao

David Porter

Follow this and additional works at: https://digitalcommons.chapman.edu/esi_working_papers

Part of the Econometrics Commons, Economic Theory Commons, and the Other Economics Commons 
Dynamic Resource Allocation with Cost Externality

Comments

ESI Working Paper 21-19 


\title{
Dynamic Resource Allocation with Cost Externality
}

\author{
Hao Zhao* David Porter ${ }^{\dagger}$
}

September 1, 2021

\begin{abstract}
The inter-temporal resource allocation efficiency of a property rights-based common-pool resource system is challenged by a cost externality when one user's extraction raises the extraction cost for others. This paper builds a dynamic resource allocation model to illustrate the efficiency loss from a standard property rights market. We then create a novel inter-temporal allocation mechanism that preserves dynamic efficiency. Our dynamic resource allocation mechanism includes an optimal planning stage where the agents collectively determine a binding extraction target for each period and a market stage where agents can exchange their extraction rights assigned within each period. The theoretical model demonstrates that our mechanism can achieve the socially optimal allocation in two specific environments. A numerical simulation of our mechanism for a general environment consistently tracks the social optimum and significantly outperforms the traditional property rights market.
\end{abstract}

JEL classification: D45, D47, D62, Q58

Keywords: Common-pool resource management, cost externality, dynamic efficiency, property rights market, optimal planning

\footnotetext{
*Economic Science Institute, Chapman University, hzhao@chapman.edu.

${ }^{\dagger}$ Economic Science Institute, Chapman University, dporter@chapman.edu.
} 


\section{Introduction}

Recent studies on common-pool resource (CPR) management have found that welldefined property rights for the CPR do not necessarily lead to efficient inter-temporal resource allocation (Anderson et al., 1983; Boyce, 1992; Gardner et al., 1997; Moxnes, 1998a,b; Costello and Deacon, 2007; Fell, 2009; Valcu and Weninger, 2013; Huang and Smith, 2014). A significant source of the dynamic inefficiency is a cost externality. ${ }^{1}$ If the cost to exploit a CPR increases with its depletion level, extraction rights holders will have an incentive to exercise their rights before others. That leads to an "extraction race" even though the total number of extraction rights is fixed for everyone. According to the estimation by Bisack and Sutinen (2006) and Huang and Smith (2014), the loss of dynamic efficiency can reach up to 20 percent of the social optimum.

Despite the substantial efficiency loss, the literature has yet to develop a solution to this extraction externality. Many have suggested delineating extraction rights more precisely, the so-called optimal planning approach (Gisser, 1983; Gardner et al., 1997; Costello and Deacon, 2007). However, the optimal plan is informationintensive and easily challenged by the uncertainty from individual heterogeneity and temporal shocks, not to mention the administrative costs when a third-party "planner" is involved in the property rights allocation process (Valcu and Weninger, 2013). In this paper, we propose a dynamic resource allocation mechanism (DRAM) that combines information aggregation, optimal planning, and market incentives to resolve the dynamic inefficiency.

The DRAM includes two stages. In an optimal planning stage, resource users collectively determine the inter-temporal resource allocation through a majority decision rule. Then in a market stage, in each period, agents start with a share of the aggregate extraction rights determined in the planning stage, with the share reflecting their initial share of property rights. They can trade their extraction rights in

\footnotetext{
${ }^{1}$ The cost externality is also referred to as a stock externality or pumping cost externality (Smith, 1977; Anderson et al., 1983; Negri, 1989; Provencher and Burt, 1993; Gardner et al., 1997; Huang and Smith, 2014).
} 
a centralized market within each period, and unused rights will expire at the end of the period.

This paper examines the effectiveness of DRAM in a theoretical model and an extension through agent-based simulations. First, we develop a dynamic model to investigate resource allocation over time under different institutions. As is commonly documented in the literature, our model confirms that a standard property rights market cannot fully resolve the "tragedy of the commons". More importantly, we characterize individual preferences over aggregate resource allocation across periods. The solution to the individual problem lays out sufficient conditions when a majority decision among the individual resource users leads to the socially optimal intertemporal resource allocation.

Specifically, our model identifies two unique environments where most resource users prefer the socially optimal resource allocation over other alternatives. The first is a homogeneous agent environment where agents' return functions are a multiplicative scaling to each other. The solution of individual preferences implies that an agent prefers the socially optimal allocation if her initial share of property rights represents the share of her extraction over total extraction in the society. The second environment is a time-consistent preference environment where individual return functions remain unchanged over time. Our model illustrates that with quadratic return functions, most agents will have an individual preference consistent with the social optimum.

The two specific environments seem to be very restrictive regarding what circumstances where the DRAM could apply. Therefore, we take the second step by simulating the dynamic resource allocation of DRAM in a general environment with individual heterogeneity, temporal shocks, and random property rights assignments, and compare its performance with the social optimum and property rights market outcomes. The simulation results suggest that the DRAM closely tracks the socially optimal allocation and consistently outperforms the standard property rights market. Given the quadratic return functions commonly adopted in the empirical literature, a majority of agents exhibit a concave preference over the inter-temporal 
resource allocation. ${ }^{2}$ Therefore, even in the most complex environment, the majority expresses a tendency to allocate resource "evenly" over time, that alleviates the extraction competition resulted from the cost externality.

The DRAM has the potential to be applied in many real-world resource allocation problems. Typical CPR systems that suffer from a cost externality include groundwater aquifers and fisheries. The cost of pumping or fishing increases with the depletion of the resource stock, incentivizing everyone to exercise extraction rights earlier. Since the return from resource extraction usually displays decreasing returns to scale due to congestion or concavity in return functions, the excessive extraction in early periods will cause a welfare loss. In DRAM, the optimal planning stage internalizes this cost externality through aggregating individual preferences over the inter-temporal resource allocation and setting a binding extraction target in each period. The binding targets avoid individual deviations caused by cost externality. Moreover, the market stage within each period ensures the allocative efficiency of the fixed extraction quotas.

The majority decision rule in the optimal planning stage is novel to the dynamic CPR management design. ${ }^{3}$ It aggregates individual preferences under a noncooperative setting, hence relaxing the prerequisite for optimal planning substantially and avoiding any inefficiency from collective bargaining and other costs (Ostrom, 1990; Ostrom et al., 1994; Grafton et al., 2006; Cancino et al., 2007; Heintzelman et al., 2009; Deacon et al., 2012; Richter et al., 2013; Holland, 2018). Real-world examples for resource allocation cooperatives have been found in groundwater and fishery management (see Costello and Deacon (2007) and Ovando et al. (2013) for examples of fishery cooperatives). For instance, in the Raymond basin of Southern California, after groundwater rights adjudication (users collectively define and ration pumping rights of the aquifer), pumping rights holders form a watermaster, an agency charged

\footnotetext{
${ }^{2}$ For example, Huang and Smith (2014) employ a quadratic function for the fishermen's value obtained from vessels. Fell (2009) and Valcu and Weninger (2013) use quadratic cost functions to establish the convexity of efforts in fishing cost that is equivalent to the concavity of efforts in return as established by the quadratic return functions.

${ }^{3}$ Walker et al. (2000) and Bernard et al. (2013) conduct experiments to investigate how binding voting affects extraction in a static open access CPR system.
} 
with administering adjudicated water rights, to determine annual extraction rights supply to the whole basin. The annual yield is adjusted according to drought cycles and deficit pumping is limited to a negligible extent to avoid over-extraction. It is noteworthy that within the watermaster, board members make decisions through majority voting. Therefore, not only is the DRAM a theoretical proposition but also it has proved practical in real-world applications.

The remainder of the paper is organized as follows. Section 2 presents the dynamic resource allocation problem and demonstrates resource allocation under the social optimum and property rights market. Section 3 introduces the dynamic resource allocation mechanism. Section 4 compares the simulated allocation outcomes under the DRAM and property rights market. Section 5 offers concluding remarks.

\section{Dynamic Resource Allocation Problem}

The presence of a cost externality results in a declining value of the CPR stock as resource is withdrawn. A standard rights-based market for the CPR can not fully capture this stock value heterogeneity and therefore does not guarantee firstbest economic outcomes. This section introduces the underlying dynamic resource allocation problem that is abstracted from rights-based CPR management, such as groundwater extraction. Within this framework, we identify the socially optimal allocation and demonstrate the inefficiency of a property rights market.

In our model, there are $N \geq 2$ agents who own extraction rights (or property rights) to a CPR. The total resource rights equal $Q$ and expire after $T \geq 2$ periods. ${ }^{4}$ Unlike the classic CPR problem, in this model, we assume that the extraction rights to the resource are well-defined and assigned to the agents before extraction. Therefore, there is no quantity externality that each agent's extraction affects the amount of resource available to others. Instead, we consider that the conflict of interests among the agents comes from the cost externality that one agent's extraction will raise the extraction cost for others. Specifically, we assume that the resource's marginal ex-

\footnotetext{
${ }^{4}$ In the example of groundwater extraction, this corresponds to the situation where $N$ pumpers share $Q$ units of groundwater stock within $T$ years.
} 
traction cost increases with the existing depletion linearly: $M C(X)=k X$, where $M C$ denotes the marginal cost, $X$ is the existing depletion level, and $k$ is a cost parameter. We further assume that the agents pay the same average extraction cost within a period. ${ }^{5}$ For example, in period $t$, the starting level of depletion, $D_{t}$, and the total amount of extraction, $X_{t}$, result in an average extraction cost $k\left(D_{t}+\frac{X_{t}}{2}\right)$ for each agent.

The return to the extracted resource differs by time and the identity of the agent. Specifically, agent $i$ 's return from extraction $x_{i t}$ in period $t$ is $f_{i t}\left(x_{i t}\right)$, where $f^{\prime \prime}(\cdot)<0$ indicates a concave return function. We also impose a boundary condition $f^{\prime}(0)>0$ and $f^{\prime}(Q)<0$ to ensure that a single agent does not use all the resource. Agent $i$ 's profit in period $t$ is the difference between her return and the total cost paid for the resource. For simplicity, we assume that there is no discount of individual utility regarding the profit across time. Therefore, an agent's target is to maximize her total profit over the $T$ periods.

In this section, we derive two resource allocation equilibria. The first is the social optimum, where the extraction by each agent $i$ in each period $t$ maximizes the total social welfare across the $T$ periods. One can think about the social optimum as the case where a social planner who knows every agent's preference assigns property rights $x_{i t}$ to agent $i$ in period $t$ that solves the social welfare maximization problem. The socially optimal allocation serves as a benchmark for comparison, as it indicates the maximal potential welfare that could be achieved in the economy.

We then move to the agent-based model and derive the equilibrium with a continuous property rights market where the agents can trade their property rights freely through the $T$ periods. In both cases, the total amount of resource extraction is limited to $Q$, which serves as an aggregate resource constraint for the economy: $\sum_{i, t} x_{i t} \leq Q$.

\footnotetext{
${ }^{5}$ There are two ways to interpret this assumption. We can think about the "period" as the minimal time instant at which the agents conduct an action, or we consider that the agents extract the resource each at a constant rate during the whole span of a "period."
} 


\subsection{Social Optimum}

Aggregating over the marginal costs, the total extraction cost across $T$ periods is

$$
\sum_{t=1, \ldots, T} k\left(D_{t}+\frac{X_{t}}{2}\right) X_{t}=\frac{k\left(\sum_{t} X_{t}\right)^{2}}{2}=\frac{k\left(\sum_{i, t} x_{i t}\right)^{2}}{2}
$$

where $X_{t}=\sum_{i} x_{i t}$ is the total extraction in period $t$. We normalize the starting level of depletion as 0 , so $D_{t}=0$ for $t=1$ and $D_{t}=\sum_{s=1, \ldots, t-1} X_{s}$ for $t>1$.

The socially optimal (SO) resource allocation is determined by maximizing the aggregate return net of the total extraction cost in $T$ periods:

$$
\max _{\left\{x_{i t} \mid i=1,2, \ldots, N ; t=1,2, \ldots, T\right\}} \sum_{i, t} f_{i t}\left(x_{i t}\right)-\frac{k\left(\sum_{i, t} x_{i t}\right)^{2}}{2} \text { s.t. } \sum_{i, t} x_{i t} \leq Q .
$$

The problem has two different sets of solutions depending on whether the resource constraint binds or not. When $Q$ is large enough, resource use by each agent is only constrained by the rising cost of extraction. At the optimum, the marginal return of resource is equalized across all agents and periods, and it is equal to the marginal cost at the end of period T. Denote the total depletion in the equilibrium by $\bar{Q}$. The socially optimal allocation is $x_{i t}^{S O}=f^{\prime-1}(k \bar{Q})$ for all $i, t$ with $\sum_{i, t} x_{i t}^{S O}=\bar{Q}$.

The second solution, which we focus on, is obtained when the aggregate resource constraint binds $(Q \leq \bar{Q})$. Unlike in the first case, the amount of resource $Q$ is relevant in the derivation of socially optimal allocation. We can think about $Q$ as a regulatory cap imposed by the government to prevent over-depletion of the resource. Under the socially optimal allocation, the resource is distributed to the agents within the limit $Q$. Since the individual return function is concave, in the equilibrium, the marginal return of resource is the same across agents and time, and the aggregate extraction equals the cap:

$$
f_{i t}^{\prime}\left(x_{i t}^{S O}\right)=f_{j s}^{\prime}\left(x_{j s}^{S O}\right) \forall i, j, t, s \text { s.t. } \quad \sum_{i, t} x_{i t}^{S O}=Q
$$




\subsection{Property Rights Market}

The equilibrium equation (3) that defines the social optimum is unlikely to hold when the agents make the extraction decisions by themselves since the extraction cost rises with depletion. Even with a well-established property rights market, it only ensures equalized marginal profit across agents within a period. However, due to the cost externality, everyone values the resource more in earlier periods, resulting in a market allocation where the resource is depleted faster than the social optimum. Below we formally illustrate the property rights market equilibrium with cost externality.

Consider an arbitrary allocation of total extraction rights $Q$ among the agents at the beginning of period 1. Denote the extraction rights held by individual $i$ at the beginning of period $t$ by $R_{i t} . \sum_{i} R_{i 1}=Q$. We assume the agents trade their rights at the beginning of each period, and trading results in an equilibrium price $p_{t}$ in period $t{ }^{6}$ Given the market price, agent $i$ first chooses her net purchase $r_{i t}$, then decides her extraction $x_{i t}$. Note that agent $i$ 's choice of extraction $x_{i t}$ will affect the amount of resource left after period $t$, hence the resource's price and allocation in all the following periods. Therefore, in period $t$, the agent solves a dynamic optimization problem

$$
\max _{\left\{x_{i s}, r_{i s}\right\}_{s \geq t}^{T}} \sum_{s \geq t}^{T}\left[f_{i t}\left(x_{i s}\right)-k\left(D_{s}+\frac{X_{s}}{2}\right) x_{i s}-p_{s} r_{i s}\right] \text { s.t. } \quad x_{i s} \leq R_{i s}+r_{i s}
$$

where the individual property rights holding $R_{i s}$ satisfies the transition equation

$$
R_{i, s+1}=R_{i s}+r_{i s}-x_{i s}
$$

The state variables of the dynamic system are the property rights allocation $R_{i t}$ for each agent $i$ at the beginning of period $t$. Denote the rights allocation across all

\footnotetext{
${ }^{6}$ The property rights market described in this model is how the standard market is implemented. Maybe there is a way to redefined the property rights to take into account the cost externality, but that would require knowledge beyond the purview of the planner.
} 
the agents in period $t$ as $\left\{R_{t}\right\}$. Agent $i$ 's value function is

$$
v_{i t}\left(\left\{R_{i t}\right\}\right)=f_{i t}\left(x_{i t}\right)-k\left(D_{t}+\frac{X_{t}}{2}\right) x_{i t}-p_{t} r_{i t}+v_{i, t+1}\left(\left\{R_{i, t+1}\right\}\right)
$$

with $R_{i, t+1}=R_{i t}+r_{i t}-x_{i t}$. Her individual optimization problem in period $t$ can be reformulated as

$$
\max _{x_{i t}, r_{i t}} v_{i t}\left(\left\{R_{i t}\right\}\right) \text { s.t. } x_{i s} \leq R_{i s}+r_{i s}
$$

There is also a market-clearing condition

$$
\sum_{i} r_{i t}=0 \quad \forall t
$$

Given $f^{\prime}(0)>0$ and the market-clearing condition, the price in the market is always non-negative: $p_{t} \geq 0$. The first-order condition for the optimization problem (7) yields a no-arbitrage condition

$$
p_{t}=p_{s} \forall t, s
$$

Denote the no-arbitrage market price by $p^{M}$, where the subscript $M$ denotes the outcome variables in the market equilibrium. The first-order condition for agent $i$ is

$$
f_{i t}^{\prime}\left(x_{i t}^{M}\right)-k\left(D_{t}^{M}+\frac{X_{t}^{M}}{2}+\frac{x_{i t}^{M}}{2}\right)=p^{M} \forall t
$$

The first-order condition and the binding resource constraint $\sum_{i, t} x_{i t}^{M}=Q$ determine the resource allocation in the property rights market equilibrium.

Moreover, the first-order condition suggests that the difference between marginal return and marginal extraction cost equals a constant for all the agents and time. As the accumulated depletion increases with time, the marginal cost of extraction also increases with time. To balance the rising cost, the equilibrium marginal benefit for each agent needs to increase with time. Compared with the social optimum, 
agents use more resources in earlier periods and fewer resources later. This result is summarized in the following proposition.

Proposition 1. There exists a period $t \in[1, T)$ that for all periods $s \leq t$, agents use more resources under the property rights market equilibrium than the social optimum $\left(X_{i s}^{M}>X_{i s}^{S O}\right)$, and for all periods $s>t$, agents use fewer resources under the property rights market equilibrium than the social optimum $\left(X_{i s}^{M}<X_{i s}^{S O}\right)$.

Proof. See Appendix B.1 for the proof.

Proposition 1 demonstrates that the straight market approach is not able to deliver a fully efficient resource allocation outcome. However, for the command-and-control regime to out-perform the market, the planner requires specific knowledge of individual preferences. Next, we will show that there is a way to fix the rights-based management system with incentives while avoiding the difficulty of information acquisition faced by the social planner.

\section{Dynamic Resource Allocation Mechanism}

So far, we have shown that the property rights market only yields a sub-optimal resource allocation when a cost externality exists. In theory, optimal planning can generate the first-best allocation, but it is difficult to design the optimal plan since the planner may not perfectly observe individual preferences. Moreover, the rigid plan may also limit the agents' ability to respond to unanticipated profit shocks.

This section introduces a market design that combines the advantages of optimal planning and the property rights market to solve the dynamic resource allocation problem. The mechanism includes two key steps. The first is an optimal planning stage where the agents collectively decide the total resource supply in each period. The second is a market stage where the total resource supply determined in the first stage is allocated to the agents through a within-period extraction rights market. 


\subsection{Market Stage}

Individual decisions in the optimal planning stage depend on the allocation outcome in the market stage. Therefore, before investigating the individual preferences over the aggregate resource allocation, we first specify rules for the market. Here we assume a perfectly competitive market, so the equilibrium price in each period always equals the agents' marginal benefit minus the average cost of extraction within that period.

Given the competitive equilibrium price $p_{t}$ and total resource supply $S_{t}$ in period $t$, the total market revenue is $p_{t} S_{t}$. In the DRAM, we impose a market revenue sharing rule that agent $i$ 's share of market revenue $\sigma_{i}$ equals her initial share of property rights: $\sigma_{i}=\frac{R_{i 1}}{Q}$. For example, this outcome can be obtained from a multi-unit ascending-bid consignment auction where total auction revenue is returned to agents according to their share $\sigma_{i}$ (Hahn and Noll, 1982; Khezr and MacKenzie, 2018). In this case, agent $i$ earns a market revenue $\sigma_{i} p_{t} S_{t}$.

Market competitiveness implies that the within-period resource allocation is efficient. The revenue share $\sigma_{i}$, as we will show later, plays an important role in correcting the distortion in agents' incentives caused by individual heterogeneity. The revenue sharing rule based on each agent's property rights share is also politically appealing since it ensures that the yield from property rights is the same across individuals. $^{7}$ All that remains in the mechanism design is to specify the rules of collective action in the optimal planning stage so that the inter-temporal resource allocation reflects the social optimum. Next, we will derive individually optimal resource supply in each period. Based on the individual preferences, we then discuss potential decision rules that can implement the optimal planning outcome.

\subsection{The Individual's Problem}

Denote the inter-temporal aggregate resource supply by $\left\{S_{t}\right\}_{t=1}^{T}$, with $\sum_{t} S_{t}=Q$. Agent $i$ prefers the allocation $\left\{S_{t}\right\}$ that solves the individual profit maximization

\footnotetext{
${ }^{7}$ Schott et al. (2007) show that output sharing provides a free-riding incentive to offset overuse in a CPR experiment.
} 
problem

$$
\max _{\left\{S_{t}\right\}} \sum_{t}\left[f_{i t}\left(x_{i t}\right)-p_{t} x_{i t}-k\left(D_{t}+\frac{S_{t}}{2}\right) x_{i t}\right]+\sigma_{i} \sum_{t} p_{t} S_{t} .
$$

In each period $t$, the individual pays a market price $p_{t}$ for each unit of resource she extracts, while she also earns $\sigma_{i} p_{t} S_{t}$ from the total market revenue according to the market revenue sharing rule. ${ }^{8}$ The agent also pays a unit extraction cost $k\left(D_{t}+\frac{S_{t}}{2}\right)$ that depends on the existing depletion $D_{t}$ and the total extraction $S_{t}$ in period $t$.

Note that, in the individual problem, the total resource constraint binds, $X_{t}=S_{t}$, for all periods $t=1, \ldots, T$. In this market design, the resource supply in each period is strictly fixed. Unused rights will forfeit and then be reallocated to others through a secondary market, and saving for the future is not allowed. In reality, there might be excessive use beyond individual rights. Agents should purchase extra rights from others to make up for any deficit through the secondary market. If the overall extraction exceeds the cap $S_{t}$, those violators must pay a large enough fine, so it is strictly preferred to abide by the resource constraint.

On the equilibrium path, the individual extraction $x_{i t}$ and market price $p_{t}$ are derived from the within-period optimization problem

$$
\max _{x_{i t}} f_{i t}\left(x_{i t}\right)-p_{t} x_{i t}-k\left(D_{t}+\frac{S_{t}}{2}\right) x_{i t}
$$

with $\sum_{i} x_{i t}=S_{t}$. Note that, the agent's share of market value $\sigma_{i} p_{t} S_{t}$ is independent of individual extraction decision since agents are price takers.

The first-order condition yields

$$
f_{i t}^{\prime}\left(x_{i t}\right)=p_{t}+k D_{t}+\frac{k S_{t}}{2}
$$

In equilibrium, every agent obtains the same marginal return since the resource price and extraction cost are the same across individuals.

\footnotetext{
${ }^{8}$ For example, in a consignment auction, the agent pays $p_{t}$ for her bid $x_{i t}$ of the resource, and receives a fraction of the auction revenue, $\sigma_{i} p_{t} S_{t}$, when the auction closes.
} 
Denote the marginal return by $K_{t}: K_{t}=p_{t}+k D_{t}+\frac{k S_{t}}{2}$. From the first-order condition, we have

$$
x_{i t}=f_{i t}^{\prime-1}\left(K_{t}\right)
$$

The period $t$ resource constraint can be rearranged as

$$
S_{t}=\sum_{i} x_{i t}=\sum_{i} f_{i t}^{\prime-1}\left(K_{t}\right)
$$

Since $f_{i t}^{\prime}$ is a decreasing function $\left(f^{\prime \prime}(\cdot)<0\right)$, there is a one-to-one mapping between total resource supply $S_{t}$ and the marginal return of extraction $K_{t}$. As a result, $K_{t}$ can be expressed as a function of $S_{t}$ : $K_{t}=K_{t}\left(S_{t}\right)$. Consequently, individual extraction $x_{i t}=f_{i t}^{\prime-1}\left(K_{t}\left(S_{t}\right)\right)$ and market price $p_{t}=K_{t}\left(S_{t}\right)-k D_{t}-\frac{k S_{t}}{2}$ are also functions of $S_{t}$

The total market revenue across $T$ periods can be expressed as

$$
\begin{aligned}
\sum_{t} p_{t} S_{t} & =\sum_{t}\left[K_{t}\left(S_{t}\right)-k D_{t}-\frac{k S_{t}}{2}\right] S_{t} \\
& =\sum_{t} K_{t}\left(S_{t}\right) S_{t}-k \frac{Q^{2}}{2}
\end{aligned}
$$

As a result, agent $i$ 's inter-temporal profit maximization problem can be rewritten as

$$
\max _{\left\{S_{t}\right\}} \sum_{t} u_{i t}\left(S_{t}\right)-\sigma_{i} k \frac{Q^{2}}{2}
$$

where $u_{i t}\left(S_{t}\right)=f_{i t}\left(x_{i t}\left(S_{t}\right)\right)-x_{i t}\left(S_{t}\right) K_{t}\left(S_{t}\right)+\sigma_{i} K_{t}\left(S_{t}\right) S_{t}$.

The first and second-order derivatives of $u_{i t}$ to $S_{t}$ are

$$
\begin{aligned}
& u_{i t}^{\prime}\left(S_{t}\right)=-x_{i t}\left(S_{t}\right) K_{t}^{\prime}\left(S_{t}\right)+\sigma_{i} S_{t} K_{t}^{\prime}\left(S_{t}\right)+\sigma_{i} K_{t}\left(S_{t}\right) \\
& u_{i t}^{\prime \prime}\left(S_{t}\right)=\left[2 \sigma_{i}-x_{i t}^{\prime}\left(S_{t}\right)\right] K_{t}^{\prime}\left(S_{t}\right)+\left[\sigma_{i} S_{t}-x_{i t}\left(S_{t}\right)\right] K_{t}^{\prime \prime}\left(S_{t}\right)
\end{aligned}
$$

The individual problem takes an interior solution at $\left\{S_{t}\right\}$ if $u_{i t}^{\prime}\left(S_{t}\right)=u_{i s}^{\prime}\left(S_{s}\right)$ for all $s, t$ and $\sum_{t} u_{i t}^{\prime \prime}\left(S_{t}\right)<0$, or a corner solution at $S_{t}=Q$ for some $t$ and $S_{s}=0$ for all 
$s \neq t$ if $\sum_{t} u_{i t}^{\prime \prime}\left(S_{t}\right)>0$. Note that, if the individual problem takes multiple extrema, the solution is the extremum that yields the highest profit.

By definition, $K_{t}\left(S_{t}\right)=f_{i t}^{\prime}\left(x_{i t}\right)$. Hence, the allocation of resources reaches the social optimum when $K_{t}\left(S_{t}\right)=K_{s}\left(S_{s}\right)$ for all $s, t=1, \ldots, T$. Therefore, the corner solution to the individual problem cannot be socially optimal. The following proposition establishes a necessary and sufficient condition for an individual interior solution to be consistent with the social optimum.

Proposition 2. Agent $i$ prefers the socially optimal allocation if and only if at the solution $\left\{S_{t}\right\}$ of the individual problem,

(C1) $\sum_{t} u_{i t}^{\prime \prime}\left(S_{t}\right)<0$ and

(C2) $u_{i t}^{\prime}\left(S_{t}\right)=u_{i s}^{\prime}\left(S_{s}\right) \Rightarrow K_{t}\left(S_{t}\right)=K_{s}\left(S_{s}\right)$.

The proof of Proposition 2 is as follows. Condition (C1) implies that the solution is an interior solution at which $u_{i t}^{\prime}\left(S_{t}\right)=u_{i s}^{\prime}\left(S_{s}\right)$ for all $s, t$. Then condition $(\mathrm{C} 2)$ demonstrates that the solution that satisfies $u_{i t}^{\prime}\left(S_{t}\right)=u_{i s}^{\prime}\left(S_{s}\right)$ also satisfies $K_{t}\left(S_{t}\right)=$ $K_{s}\left(S_{s}\right)$, or $f_{t}^{\prime}(\cdot)=f_{s}^{\prime}(\cdot)$, the equation that defines the social optimum. Combining the two conditions, we obtain the result that the individual preference is equivalent to the social optimum.

To check the necessary and sufficient conditions, we need to solve the individual problem and evaluate the first and second-order conditions at the solution. That requires detailed model specifications to calculate $u_{i}^{\prime}\left(S_{t}\right)$ and $u_{i}^{\prime \prime}\left(S_{t}\right)$ in each period. To avoid such complexity, we examine a set of stricter conditions that preserve the sufficiency to establish the equivalence between individual preference and social optimum.

Following Proposition 2, a sufficient condition for the equivalence between individual preference and social optimum is that for all $\left\{S_{t}\right\}$,

$\left(C 1^{\prime}\right) u_{i t}^{\prime \prime}\left(S_{t}\right)<0$ and

$\left(C \mathscr{2}^{\prime}\right) u_{i t}^{\prime}\left(S_{t}\right)=u_{i s}^{\prime}\left(S_{s}\right) \Rightarrow K_{t}\left(S_{t}\right)=K_{s}\left(S_{s}\right)$. 
Note that if the individual problem has a unique extremum, condition $\left(\mathrm{C} 2^{\prime}\right)$ is the same as the necessary condition $(\mathrm{C} 2)$. As for condition $(\mathrm{C} 1)$, the necessity only requires $\sum_{t} u_{i t}^{\prime \prime}\left(S_{t}\right)<0$, which can hold even if in some periods, $u_{i}^{\prime \prime}\left(S_{t}\right)>0$. Applying the stricter version $u_{i}^{\prime \prime}\left(S_{t}\right)<0$ only requires checking the sign of each $u_{i}^{\prime \prime}\left(S_{t}\right)$. Since both conditions $\left(\mathrm{C}^{\prime}\right)$ and $\left(\mathrm{C}^{\prime}\right)$ are stricter than the original conditions $(\mathrm{C} 1)$ and (C2), they are sufficient to align individual preferences with the social optimum.

In this model, individual return functions differ by two dimensions: agent identity and time. As shown by equations (17) and (18), when heterogeneity exists in both dimensions, an agent's preference over aggregate resource allocation is not guaranteed to satisfy the sufficient conditions $\left(\mathrm{C}^{\prime}\right)$ and $\left(\mathrm{C}^{\prime}\right)$. Hence the individual may not prefer the socially optimal resource allocation. However, since

$$
\begin{aligned}
& \sum_{i} u_{i t}^{\prime}\left(S_{t}\right)=K_{t}\left(S_{t}\right) \\
& \sum_{i} u_{i}^{\prime \prime}\left(S_{t}\right)=K_{t}^{\prime}\left(S_{t}\right)
\end{aligned}
$$

and

$$
K_{t}^{\prime}\left(S_{t}\right)=\frac{d K_{t}}{d S_{t}}=\frac{1}{\frac{d S_{t}}{d K_{t}}}=\frac{1}{\sum_{i} \frac{1}{f_{i t}^{\prime \prime}\left(f_{i t}^{\prime}{ }^{-1}\left(K_{t}\right)\right)}}<0
$$

the whole society, or the "average" agent, prefers the social optimum. It follows that every agent will prefer the social optimum if the return function and initial property rights share are the same for all agents.

Beyond the "average" agent, our model also identifies two specific environments where a majority of agents will prefer the optimal plan. The first is a homogeneous agent environment, where in each period, agents' return functions are a multiplicative scaling to each other. The second is a time-consistent preference environment where individual return functions are quadratic and consistent over time. In the following two subsections, we will develop the formal model of the two environments and present the corresponding designs of the dynamic resource allocation mechanism. 


\subsection{Homogeneous Agents}

Previously we have shown that all agents prefer the social optimum if their initial property rights shares and return functions within each period are identical. We extend this result to the environment where individual return functions are a multiplicative scaling to each other.

Define two agents $i, j$ as homogeneous agents if there exists a constant $\mu_{i j}$ such that $i$ 's return equals $\mu_{i j}$ times of $j$ 's return when $i$ 's extraction equals $\mu_{i j}$ times of $j$ 's extraction. Namely,

$$
f_{i t}\left(\mu_{i j} x_{j t}\right)=\mu_{i j} f_{j t}\left(x_{j t}\right) .
$$

$\mu_{i j}$ captures the relative "size" of $i$ and $j$. For example, if $\mu_{i j}=2, i$ 's return from extraction $2 x_{j t}$ equals twice of $j$ 's return from extraction $x_{j t}$, or $i$ behaves as two $j$ 's together. By definition, $\mu_{i j} \mu_{j i}=1$, and $\mu_{i j}$ is constant over time.

This condition can be found with a group of farmers who share a groundwater basin. Suppose the return of water at each acre of farmland is constant, and other sources of economies of scale are negligible. Then one farmer using $x$ units of water to irrigate $\mu$ acres of land generates the same return as $\mu$ farmers using $\frac{x}{\mu}$ units of water to irrigate 1 acre of land.

In an environment where all agents are homogeneous to each other, we can express every agent $j$ 's return using the return function of $i: f_{j t}\left(x_{j t}\right)=\frac{1}{\mu_{i j}} f_{i t}\left(\mu_{i j} x_{j t}\right)$. It follows

$$
\begin{aligned}
f_{j t}^{\prime}\left(x_{j t}\right) & =\frac{1}{\mu_{i j}} f_{i t}^{\prime}\left(\mu_{i j} x_{j t}\right) \cdot \mu_{i j}=f_{i t}^{\prime}\left(\mu_{i j} x_{j t}\right) \\
f_{j t}^{\prime \prime}\left(x_{j t}\right) & =f_{i t}^{\prime \prime}\left(\mu_{i j} x_{j t}\right) \cdot \mu_{i j} .
\end{aligned}
$$

As shown in equation (13), in the equilibrium, every agent receives the same marginal return: $f_{i t}^{\prime}\left(x_{i t}\right)=f_{j t}^{\prime}\left(x_{j t}\right)=K_{t}\left(S_{t}\right)$ for all $i, j$. According to equation (23), the equilibrium extractions by individual $i$ and $j$ must satisfy the following equation

$$
x_{i t}=\mu_{i j} x_{j t} .
$$


Since $\mu_{i j}$ is constant over time, in each period $t$, agent $i$ takes a fraction $\frac{\mu_{i j}}{\sum_{i} \mu_{i j}}$ of total resource supply $S_{t}$, which also represents $i$ 's return share and is also constant over time.

Meanwhile, by equations (14) and (21),

$$
x_{i t}^{\prime}\left(S_{t}\right)=\frac{1}{f_{i t}^{\prime \prime}\left(f_{i t}^{\prime-1}\left(K_{t}\right)\right)} K_{t}^{\prime}\left(S_{t}\right)=\frac{\frac{1}{f_{i t}^{\prime \prime}\left(f_{i t}^{\prime}{ }^{-1}\left(K_{t}\right)\right)}}{\sum_{i} \frac{1}{f_{i t}^{\prime \prime}\left(f_{i t}^{\prime}-1\left(K_{t}\right)\right)}}=\frac{\frac{1}{f_{i t}^{\prime \prime}\left(x_{i t}\right)}}{\sum_{i} \frac{1}{f_{i t}^{\prime \prime}\left(x_{i t}\right)}} .
$$

According to equation (24), $\frac{1}{f_{i t}^{\prime \prime}\left(x_{i t}\right)}=\mu_{i j} \frac{1}{f_{j t}^{\prime \prime}\left(x_{j t}\right)}$ when $x_{i t}=\mu_{i j} x_{j t}$. Hence in the equilibrium,

$$
x_{i t}^{\prime}\left(S_{t}\right)=\frac{\frac{1}{f_{i t}^{\prime \prime}\left(x_{i t}\right)}}{\sum_{i} \frac{1}{f_{i t}^{\prime \prime}\left(x_{i t}\right)}}=\frac{\mu_{i j}}{\sum_{i} \mu_{i j}},
$$

which also equals agent $i$ 's extraction share in each period.

Therefore, if the initial property rights allocation is set to be $\sigma_{i}=\frac{\mu_{i j}}{\sum_{i} \mu_{i j}}$, agent $i$ 's individual problem has the following first and second-order derivatives of $u_{i t}$ with respect to $S_{t}$ :

$$
\begin{aligned}
& u_{i t}^{\prime}\left(S_{t}\right)=\sigma_{i} K_{t}\left(S_{t}\right) \\
& u_{i t}^{\prime \prime}\left(S_{t}\right)=\sigma_{i} K_{t}^{\prime}\left(S_{t}\right) .
\end{aligned}
$$

Equation $(21)$ confirms that $K_{t}^{\prime}\left(S_{t}\right)<0$. As a result, the sufficient conditions $\left(\mathrm{C}^{\prime}\right)$ and $\left(\mathrm{C}^{\prime}\right)$ hold, and we have the following proposition.

Proposition 3. If the resource users are homogeneous agents, and if agent $i$ 's initial property rights share $\sigma_{i}=\frac{\mu_{i j}}{\sum_{i} \mu_{i j}}$, the agent will prefer the socially optimal intertemporal resource supply, $S_{t}=\sum_{i} x_{i t}^{S O}$, over all other allocations.

The specific DRAM design should include

Step 1: Each agent $i$ is assigned $\sigma_{i}=\frac{\mu_{i j}}{\sum_{i} \mu_{i j}}$ share of resource rights;

Step 2: In the optimal planning stage, any subset of the agents decide the aggregate resource supply $\left\{S_{t}\right\}$ over the $T$ periods; 
Step 3: In the market stage, participants can trade their shares of the resource supply $S_{t}$ in each period $t$.

The property rights assignment in step 1 is usually referred to as "grandfathering". Although the regulator may not perfectly observe each agent's return function, he can infer the relative size of agents, $\mu_{i j}$, by checking their historical production or resource extraction. In this case, trading the share of resource rights has to be associated with the trading of the production units such as land, so that after the trade, an agent's share of property rights still equals her extraction share in each period.

According to Proposition 3, an agent $i$ will prefer the socially optimal allocation plan if her initial property rights share $\sigma_{i}=\frac{\mu_{i j}}{\sum_{i} \mu_{i j}}$. Therefore, if the property rights assignment follows the "grandfathering" principle, every agent in this economy will prefer the optimal plan. Hence in the optimal planning stage, anyone can make the socially optimal choice of $\left\{S_{t}\right\}$. Consequently, in the market stage, since each agent's share of market revenue equals her initial share of property rights, the market reaches a no-trade equilibrium. Nobody will sell or purchase additional extraction rights at the competitive price. Therefore, the market is redundant and can be replaced by an allocation rule that each agent $i$ receives $\sigma_{i}$ share of the resource supply in each period.

A caveat to the DRAM design in the homogeneous agent environment is that the initial property rights assignment $\sigma_{i}$ needs to strictly follow the size ratio $\frac{\mu_{i j}}{\sum_{i} \mu_{i j}}$. Any disturbance that causes $\sigma_{i}$ to deviate from the ratio will result in an individual preference different from the social optimum. A potential way to fix the "mistake" in the property rights assignment process is to introduce a majority decision rule in the optimal planning stage. In that case, as long as most agents' property rights share reflects the size ratio, a majority decision can still yield the socially optimal resource allocation. A well-functioning market in the market stage is then required to fix the deviation in $\sigma_{i}$ so that the within-period resource allocation is efficient.

In this model, we have shown that when the users are homogeneous agents, resource allocation can achieve social optimum if the inter-temporal resource allocation 
is determined by the agents themselves. Compared with the DRAM, optimal planning by the regulator might be infeasible as it requires access to agents' private information of return functions in each period. Moreover, the return functions may change over time due to unexpected profit shocks. The DRAM can account for the shock by repeating the optimal planning stage at the beginning of each period, while an optimal plan set by the regulator might be inflexible to make such adjustments.

\subsection{Time-Consistent Preferences}

The other case where the DRAM can generate the socially optimal allocation is when the agents' preferences are consistent over time: $f_{i t}(x)=f_{i s}(x)$ for all $s, t{ }^{9}$

In the time-consistent preference environment, specifically, we assume that the agents' return functions are quadratic. It follows that $f^{\prime \prime \prime}(x)=0$ and

$$
K^{\prime \prime}(S)=-\frac{\frac{d^{2} S}{d K^{2}}}{\left(\frac{d S}{d K}\right)^{3}}=0
$$

since $\frac{d^{2} S}{d K^{2}}=-\sum_{i} \frac{f_{i}^{\prime \prime \prime}\left(f_{i}^{\prime-1}(K)\right)}{\left(f^{\prime \prime}\left(f_{i}^{\prime-1}(K)\right)\right)^{3}}=0$. As a result, the first and second-order derivatives of $u_{i t}$ with respect to $S_{t}$ in agent $i$ 's problem are

$$
\begin{aligned}
u_{i t}^{\prime}\left(S_{t}\right) & =-x_{i}\left(S_{t}\right) K^{\prime}\left(S_{t}\right)+\sigma_{i} S_{t} K^{\prime}\left(S_{t}\right)+\sigma_{i} K\left(S_{t}\right) \\
u_{i t}^{\prime \prime}\left(S_{t}\right) & =\left[2 \sigma_{i}-x_{i}^{\prime}\left(S_{t}\right)\right] K^{\prime}\left(S_{t}\right) .
\end{aligned}
$$

\footnotetext{
${ }^{9}$ The time-consistency of individual preferences is challenged by profit shocks that occur over time. However, if the profit shocks are unanticipated, the consistency still holds ex ante. Namely, in period $t$, agent $i$ perceives $f_{i s}(x)=f_{i t}(x)$ for the future period $s>t$, even though an unexpected shock in period $s$ may cause $f_{i s}(x) \neq f_{i t}(x)$ ex post. Given the ex ante time-consistent preferences, the allocation outcome under DRAM is ex ante optimal.

If the profit shocks are predictable, the time-consistency of preferences shall still hold in a complete market environment where financial tools are created to hedge the foreseeable risk. For example, oil prices fluctuate with economic cycles that may cause heterogeneity in the value of oil extraction over time. However, oil companies can sell oil futures in the financial market to lock in profits, and thus the pumpers' preferences over extraction could still be considered time-consistent.
} 
$\left(\mathrm{C} 2^{\prime}\right)$ of the sufficient condition always holds since $u_{i t}^{\prime}\left(S_{t}\right)$ is independent of time. Let $\sigma_{i}$, agent $i$ 's property rights share, also represents her decision power in the collective decision-making process. Define a majority $J$ as a set of agents whose total decision power exceeds $1 / 2$ :

$$
J=\left\{j_{1}, j_{2}, \ldots j_{m}, \ldots, j_{M} \mid \sum_{m=1, \ldots, M} \sigma_{j_{m}}>\frac{1}{2}\right\}
$$

We show that $\left(\mathrm{C}^{\prime}\right)$ of the sufficient condition holds for a majority in the following lemma.

Lemma 1. There exists a majority set $J$ such that $u_{j_{m} t}^{\prime \prime}\left(S_{t}\right)<0$ for all $j_{m} \in J$.

Proof. See Appendix B.2 for the proof.

As the sufficient condition holds for a majority of agents, the socially optimal allocation can be implemented through majority decision-making.

Proposition 4. If the resource users have time-consistent preferences, and if individual return functions are quadratic, there exists a majority $J$ who prefers the socially optimal property rights allocation, $S_{t}=\sum_{i} x_{i t}^{S O}$, over all other allocations.

The specific DRAM design should include

Step 1: In the optimal planning stage, agents decide the aggregate resource supply $\left\{S_{t}\right\}$ over the $T$ periods through a majority decision-making procedure;

Step 2: In the market stage, participants can trade their shares of the resource supply $S_{t}$ in each period $t$.

Unlike in the homogeneous agent model, when the agents have time-consistent preferences, the initial assignment of property rights $\sigma_{i}$ is irrelevant to the DRAM allocation. However, in the optimal planning stage, the decision-making rule is stricter, as it requires a majority to determine the socially optimal allocation. A well-functioning market in the market stage is also necessary to induce within-period allocative efficiency. 
As for the detailed majority decision-making mechanism, since a majority strictly prefers the socially optimal allocation, any mechanism that abides the majority's preference will work. For example, the policymakers can collect supply allocation proposals from the agents and ask them to vote for their preferred proposal. The median voter, weighted by decision power, will decide the allocation. ${ }^{10}$ Note that, since individual preferences are fixed over time, the resources are equally distributed over time in the socially optimal allocation: $S_{t}=\frac{Q}{T}$. Therefore, the social optimum is public information, and the majority decision making could be organized as a majority voting system where agents vote over $S_{t}=\frac{Q}{T}$ and other alternatives.

In this environment, a third party like the government can implement the optimal plan directly. However, since the initial property rights allocation $\sigma_{i}$ is arbitrarily determined, a subset of agents might have a convex preference over the aggregate resource allocation: $\sum_{t} u_{i t}^{\prime \prime}\left(S_{t}\right)>0$ (see the proof of Lemma 1 in Appendix B.2). Those agents strictly prefer an extreme allocation with $S_{t}=Q$ for some $t$ and $S_{s}=0$ for $s \neq t$. Thus, the government's optimal plan may face severe resistance from a subset of the population, and majority voting might be more politically acceptable.

In summary, the DRAM design to apply to a general environment is as follows:

Step 1: Each agent $i$ is assigned $\sigma_{i}=\frac{\mu_{i j}}{\sum_{i} \mu_{i j}}$ share of resource rights;

Step 2: In the optimal planning stage, agents decide the aggregate resource supply $\left\{S_{t}\right\}$ over the $T$ periods through a majority decision-making procedure;

Step 3: In the market stage, participants can trade their shares of the resource supply $S_{t}$ in each period $t$.

\footnotetext{
${ }^{10}$ The water districts in adjudicated basins of Southern California have adopted a similar decisionmaking structure. A water district usually establishes a management board with the board seats distributed to pumping rights holders based on their rights share. The board will collectively decide the total pumping rights available (the so-called varying safe yield) each year.
} 


\section{Comparison of DRAM and Market Allocation in a General Environment: Numerical Simulations}

Our theory has revealed that the DRAM can generate the socially optimal resource allocation in a homogeneous agent or time-consistent preference environment. However, in a general environment where individual heterogeneity and temporal shocks coexist, the DRAM does not guarantee a social optimum. An interesting question remains as to how well the DRAM performs in a general environment, especially when compared to the standard property rights-based market. To provide some insights into this comparison, we run numerical simulations of the DRAM and market allocation outcomes in an environment where the return functions vary across both agents and time.

Consider the following form of the return function for agent $i$ in period $t$ :

$$
f_{i t}(x)=-\mu_{i j}\left(a+\zeta_{t}+b_{i}-\frac{x}{\mu_{i j}}\right)^{2}+c_{i}
$$

where $\mu_{i j}$ is the relative size of $i$ to $j$ as defined in the homogeneous agent model; $\zeta_{t}$ is a common shock to all agents that differs by time; $b_{i}$ and $c_{i}$ are individual heterogeneity that is constant over time. When $b_{i}=b_{j}$ for all $i, j$, the individual return function fits a homogeneous agent environment. ${ }^{11}$ When $\zeta_{t}=\zeta_{s}$ for all $s, t$, the return function fits a time-consistent preference environment.

The parameter values applied in the simulations are shown in Appendix Table A.1. Specifically, the relative agent size $\mu_{i j}$ is evenly distributed over the range $[1,4]$ (namely, the largest agent's size is around four times the size of the smallest agent). The individual property rights share $\sigma_{i}$ is initially set as $\sigma_{i}=\frac{\mu_{i j}}{\sum_{i} \mu_{i j}}$. The individual heterogeneity factor $b_{i}$ and temporal profit shock $\zeta_{t}$ are drawn from a uniform distribution $U(0,1)$. The two random sequences $b_{i}$ and $\zeta_{t}$ are depicted in Figure 1 to illustrate their volatility.

\footnotetext{
${ }^{11}$ Although a strict definition of homogeneous agent also requires that $c_{i}=\mu_{i j} c_{j}$, the constant term does not affect the decision on $x_{i}$ since it is not included in the marginal return function.
} 


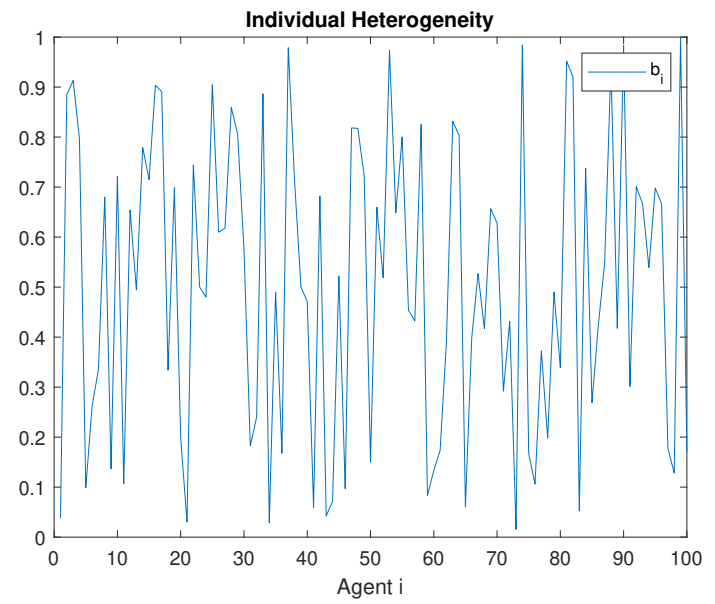

(a)

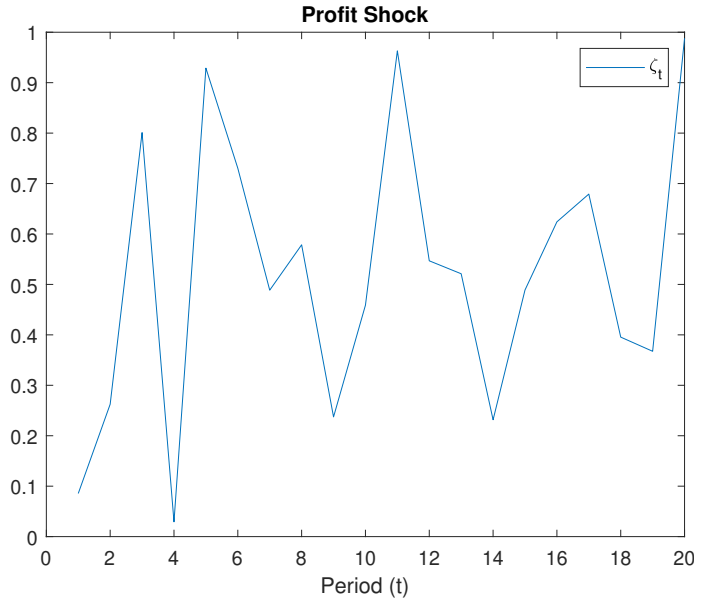

(b)

Figure 1: Simulation of Random Factors $b_{i}$ and $\zeta_{t}$

Note: This figure illustrates the volatility of random parameters used in the numerical simulations. Sub-figure 1(a) demonstrates individual specific profit terms among the 100 agents. Sub-figure 1(b) demonstrates the common profit shocks over the 20 periods.

In the simulation, we make three critical assumptions on agents' behavior. First, we assume that the agents have full information on individual heterogeneity $b_{i}$, temporal shock $\zeta_{t}$ and property rights share $\sigma_{i}$ across all the $T$ periods. Therefore, even in a non-stationary environment where individual heterogeneity and property rights share change over time, and temporal shocks vary across individuals, the agents fully anticipate those variations and can make decisions accordingly. The second assumption is that in the optimal planning stage, agents always reveal their true preference regarding the inter-temporal allocation of resource. Therefore, the majority decision-making process always conforms to the median voter's choice. ${ }^{12}$ Lastly, we assume that the extraction rights trading always reaches competitive equilibrium in the market stage. The three assumptions simplify the process to find the equilibrium allocation outcomes under different institutions, while we also acknowledge

\footnotetext{
${ }^{12}$ Theoretically, a majority of agents could form a coalition to obtain a more preferred intertemporal allocation than the medium voter's allocation scheme, as shown in Boylan et al. (1996). However, according to the experimental results in Boylan et al. (1991), in an anonymous voting environment, the majority decision is likely to converge to the medium voter's preference.
} 
that the comparison between DRAM and property rights-based market allocations does not hinge on any of the three conditions.

The simulation for each resource allocation regime proceeds as follows. In the property rights market equilibrium, there is a no-arbitrage resource price $p^{M}$ that applies to every agent and period. Hence the market allocation can be simulated following the procedure:

1. Calculate each agent's demand for extraction rights $x_{i t}$ in each period given a resource price $p$

2. solve for the value $p$ such that $\sum_{i, t} x_{i t}=Q$;

3. calculate $x_{i t}$ and $f\left(x_{i t}\right)$ given $p$.

The social optimum is achieved when marginal returns are equalized across individuals and time. Hence the socially optimal allocation can be simulated following the procedure:

1. Calculate each agent's demand for extraction rights $x_{i t}$ in each period when marginal return equals $p$;

2. solve for the value $p$ such that $\sum_{i, t} x_{i t}=Q$;

3. calculate $x_{i t}$ and $f\left(x_{i t}\right)$ given $p$.

For the DRAM allocation, in the optimal planning stage, each agent reveals her preference over the aggregate source supply scheme $\left\{S_{t}\right\}$, and the social choice is determined by the median voter (weighted by agents' decision power $\sigma_{i}$ ). Note that, since the identity of median voter may change over time, the optimal planning stage needs to be repeated at the beginning of each period. The social choice of $S_{s}$ in period $s$ can be simulated following the procedure:

1. Calculate each agent's demand for extraction rights $x_{i t}$ in period $t \geq s$ given a resource price $p_{t}$, the aggregate resource allocation plan $\left\{S_{t}\right\}_{t \geq s}$, and the existing depletion $D_{s}$ before period $s$;

2. solve for the value $p_{t}$ such that $\sum_{i} x_{i t}=S_{t}$;

3. calculate each agent's return $f_{i t}\left(x_{i t}\right)$ given $p_{t}$ and $S_{t}$;

4. calculate each agent's total return $\sum_{t \geq s} f_{i t}$ given $\left\{S_{t}\right\}_{t \geq s}$; 
5. solve for the $\left\{S_{i t}\right\}_{t \geq s}$ that maximizes each agent's total return subject to the resource constraint $\sum_{t \geq s} S_{i t}=Q-D_{s}$;

6. find the weighted median of $S_{i s}$ with the weights being each agent's property rights share $\sigma_{i}$.

We run the procedure above from period 1. After determining the social choice of $S_{1}$, we can calculate $D_{2}$ and then simulate the social choice of $S_{2}$. The same process repeats until the last period. Given the social choice of $\left\{S_{t}\right\}$, we can finally calculate individual extraction and return $x_{i t}$ and $f\left(x_{i t}\right)$ accordingly. The social extraction and return is calculated by summing up individual values in each period.

Next, we will present the simulated social extraction and return over time in the two baseline environments. Then we allow $\zeta_{t}$ and $b_{i}$ to vary simultaneously. Note that the heterogeneity within $b_{i}$ and $\zeta_{t}$ are independent of each other; namely, the same individual heterogeneity persists over time. We will relax this condition by shuffling $b_{i}$ in each period. We also mix $\sigma_{i}$, the agents' property rights share, to differentiate the environment from the homogeneous agent model. Lastly, we augment the random factors to examine how the DRAM performs in an adequately volatile environment.

\subsection{Baseline Environments}

A homogeneous agent environment requires $b_{i}=b_{j}$ for any agents $i, j$. Hence we replace $b_{i}$ by $\frac{1}{N} \sum_{t} b_{i}$, its average value over the $N$ agents. The simulated social extraction and return in each period are presented in Figure 2. In the time-consistent preference environment, we replace the temporal shock $\zeta_{t}$ by $\frac{1}{T} \sum_{t} \zeta_{t}$, its average value over the $T$ periods. The simulated social extraction and return in each period are presented in Figure 3. In both figures, the temporal and accumulated social extraction are shown in the left panels, and the corresponding social returns are shown in the right panels. The aggregate social returns are representative for overall efficiency since the total extraction costs are the same under different regimes.

The simulated results confirm our theoretical prediction that the DRAM is superior to the standard property rights market in the two baseline environments. In both cases, the market extraction is too high in the first several periods (Sub-figures 2(a) 


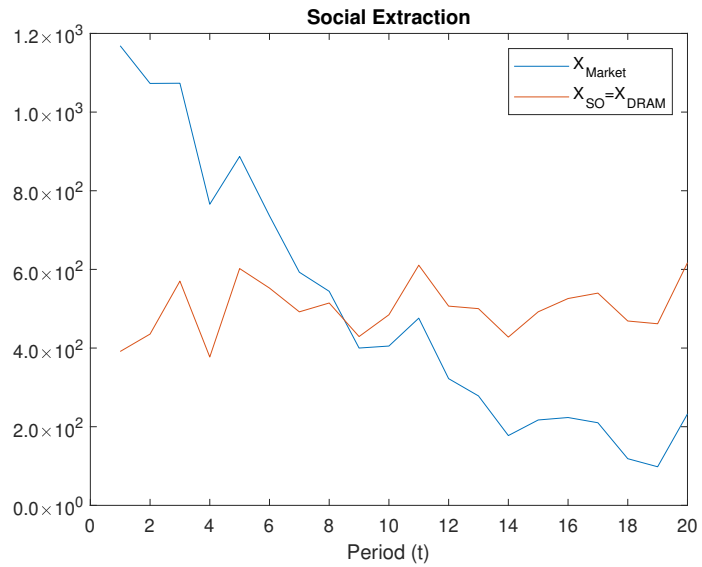

(a)

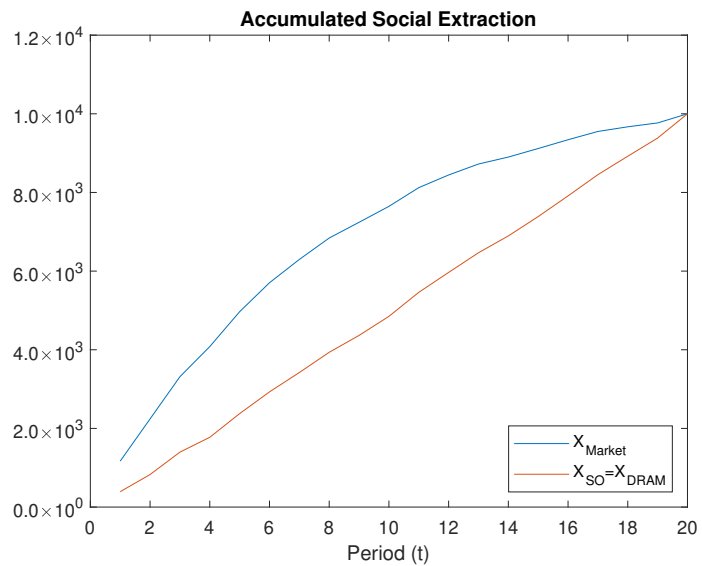

(c)

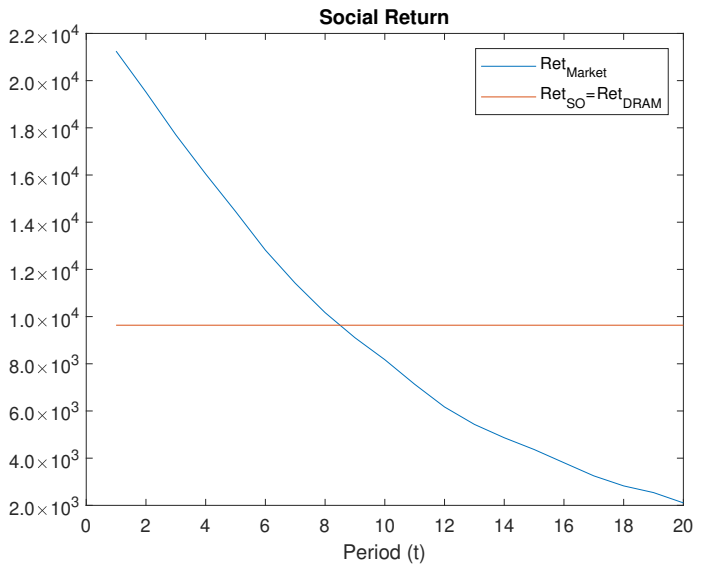

(b)

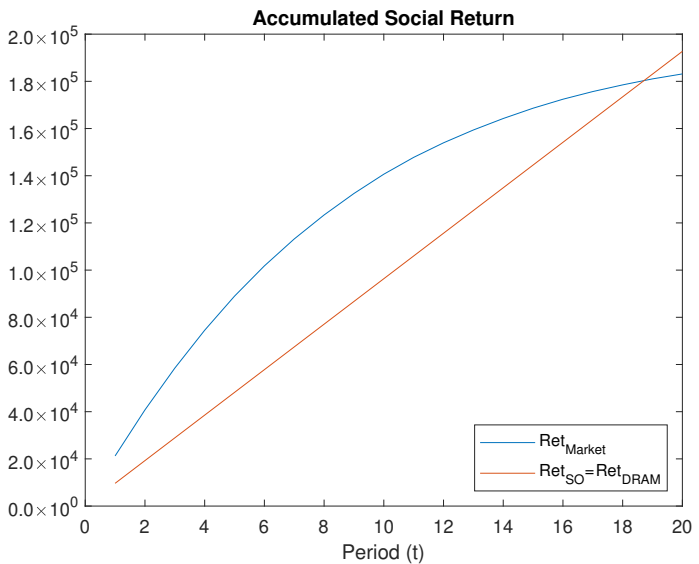

(d)

Figure 2: Homogeneous Agent Environment

Note: This figure compares the DRAM/SO and property rights market allocations over 20 periods in a homogeneous agent environment with temporal profit shocks. Sub-figure 2(a) demonstrates temporal social extractions. Sub-figure 2(b) demonstrates temporal social returns. Sub-figure 2(c) demonstrates accumulated social extractions. Sub-figure 2(d) demonstrates accumulated social returns.

and 3(a)), depleting the resource much faster than the socially optimal rate. Based on the quadratic return functions, the DRAM/SO allocation results in a constant social return over time (Sub-figures $2(\mathrm{~b})$ and $3(\mathrm{~b})$ ). The market allocation yields a 


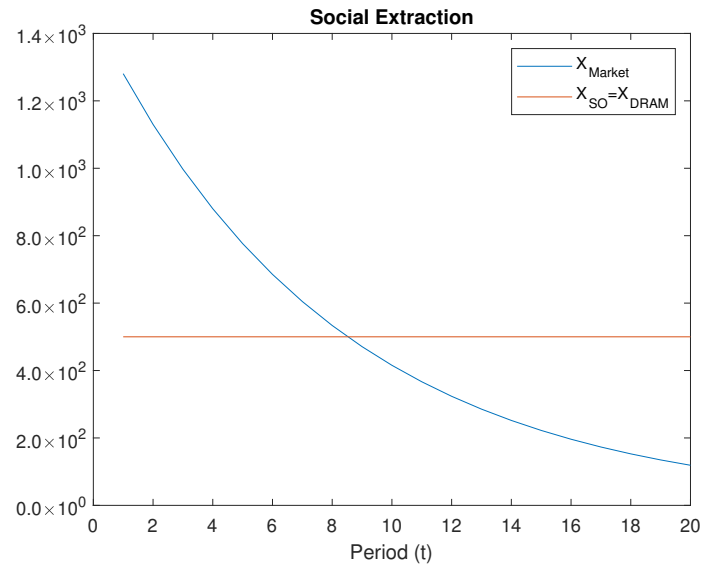

(a)

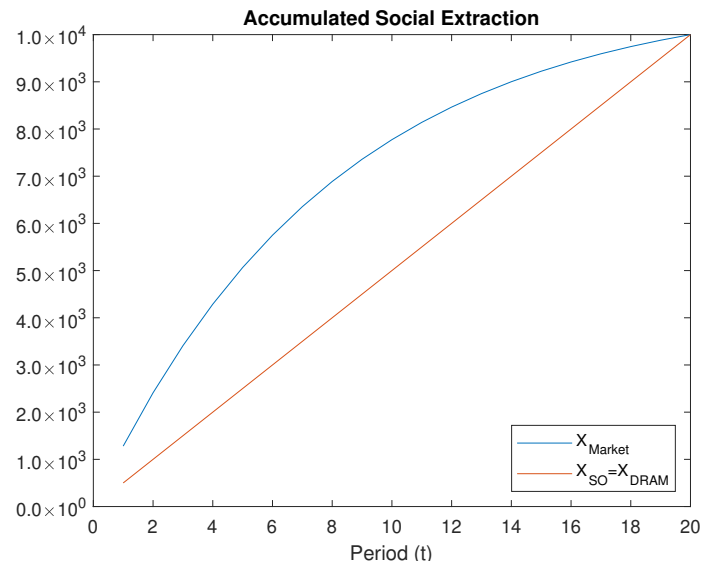

(c)

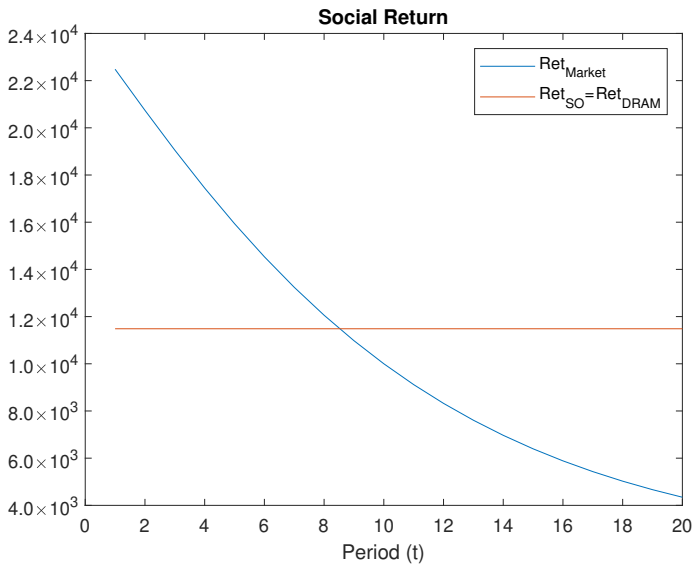

(b)

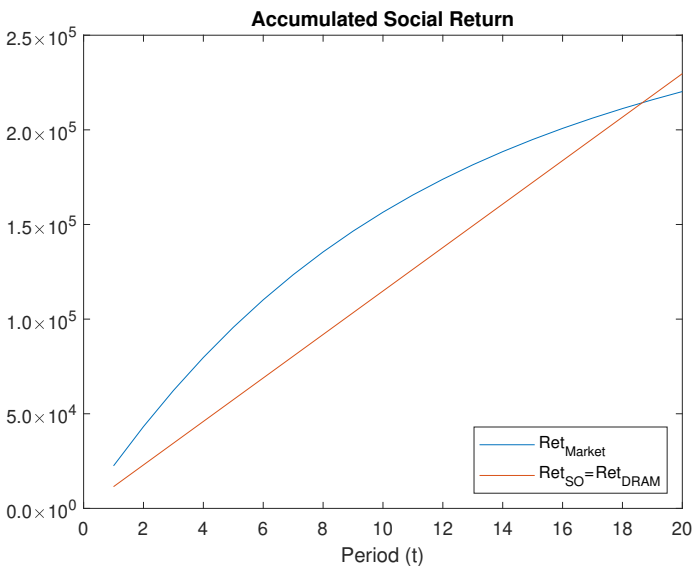

(d)

\section{Figure 3: Time-Consistent Preference Environment}

Note: This figure compares the DRAM/SO and property rights market allocations over 20 periods in a time-consistent preference environment with individual heterogeneity. Sub-figure 3(a) demonstrates temporal social extractions. Sub-figure 3(b) demonstrates temporal social returns. Sub-figure 3(c) demonstrates accumulated social extractions. Sub-figure 3(d) demonstrates accumulated social returns.

higher return in early periods as a result of over depletion, but a lower total social return over the whole time span (Sub-figures $2(\mathrm{~d})$ and $3(\mathrm{~d})$ ). 
It is noteworthy that the simulated results in both environments are very similar, except for the temporal social extraction. In the homogeneous environment, the profit shocks are reflected in the extraction (Sub-figure 2(a)). While in the timeconsistent preference environment, since the agents' return functions do not change over time, social extraction per period does not display any volatility. As a result, social extraction is constant under the DRAM/SO allocation and is smoothly declining in the market allocation (Sub-figure 3(a)).

\subsection{General Environment}

Figure 4 presents the simulated results in a general environment where both $b_{i}$ and $\zeta_{t}$ follow the simulated shocks illustrated in Figure 1. The simulated outcomes are similar to the results in the homogeneous agent environment (Figure 2). Surprisingly, the DRAM allocation seems to overlap with SO. Even in Sub-figure 4(c) when we compare the DRAM with $\mathrm{SO}$ alone, the social extraction in the two regimes is not distinguishable. The differences between the two regimes are only observable in Subfigure 4(d), where the social return resulted from the DRAM displays some level of volatility, reflecting the temporal profit shock $\zeta_{t}$. However, the magnitude of fluctuation is tiny, making it indistinguishable when comparing the two regimes with the property rights market allocation.

The simulation results suggest that even when individual heterogeneity and temporal shocks exist simultaneously, the DRAM performs better than the property rights market in terms of resource allocation efficiency if the two dimensions of heterogeneity are independent of each other. In such an environment, the size ranking among agents keeps the same over time, resulting in a situation similar to the homogeneous agent environment. In reality, the relative size of resource users usually does not change dramatically over time. Therefore, the DRAM is likely to perform better than the property rights market.

The fact that agent composition in the general environment is similar to that in the homogeneous agent environment is the main cause of consistency between the DRAM and SO allocations. Therefore, we expect the DRAM allocations to deviate 


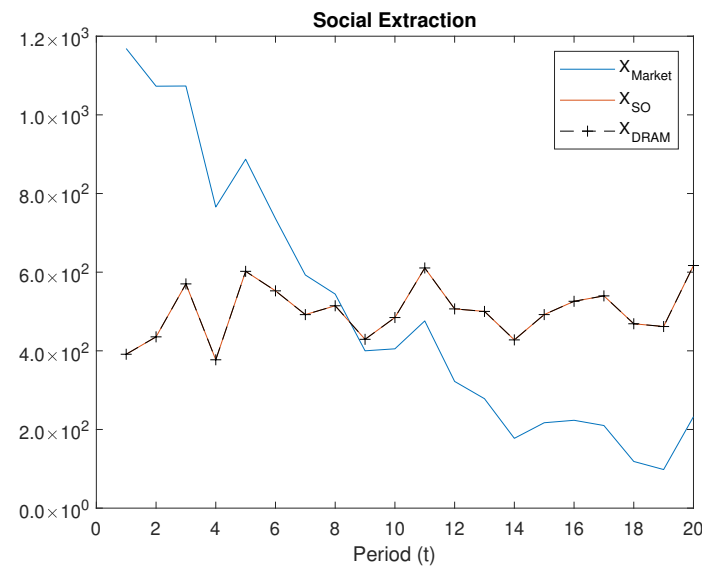

(a)

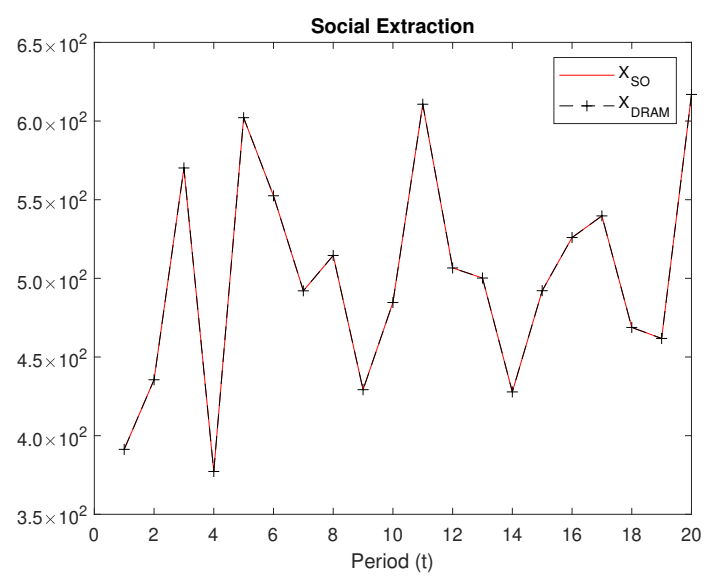

(c)

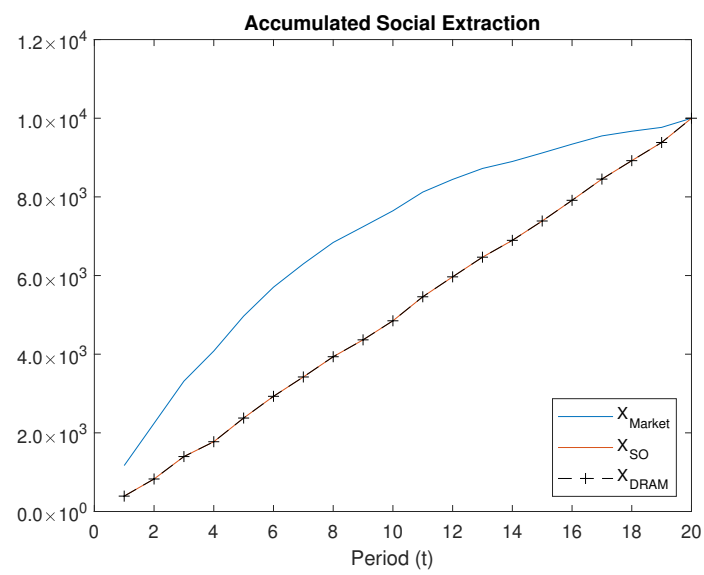

(e)

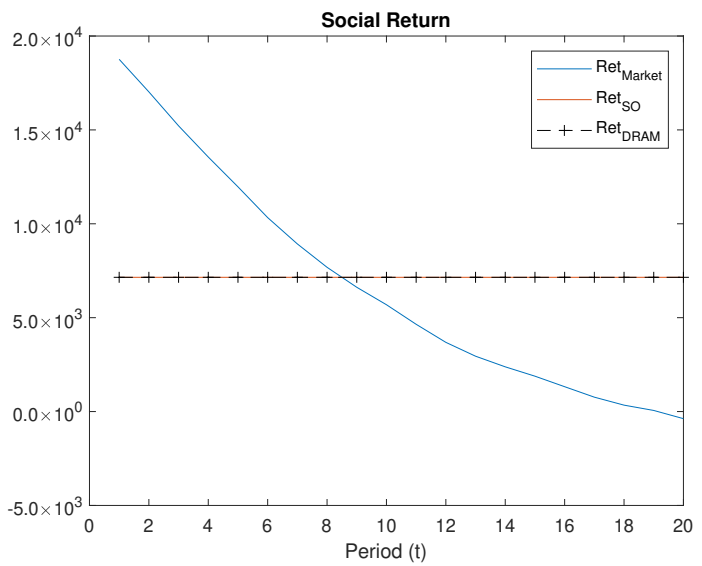

(b)

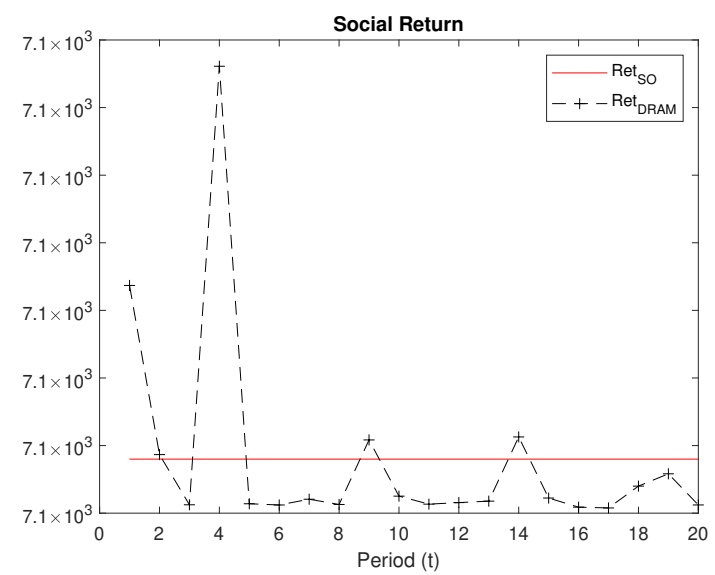

(d)

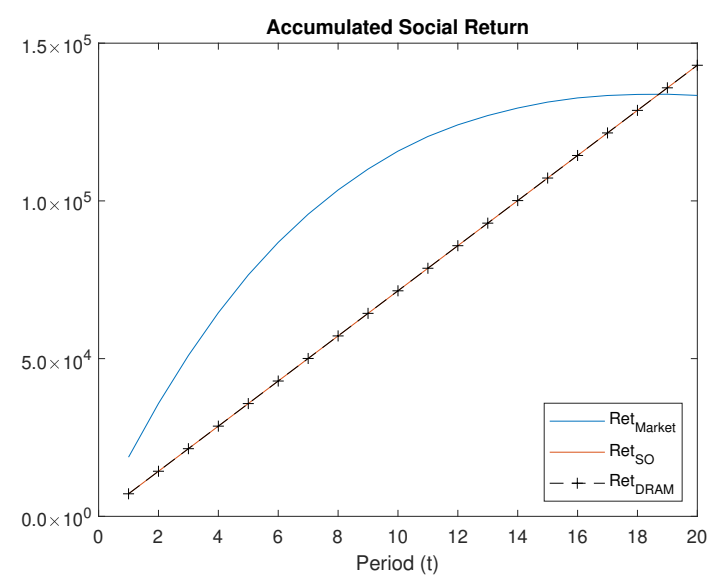

(f)

Figure 4: General Environment

Note: This figure compares the DRAM, SO and property rights market allocations over 20 periods in a general environment with temporal profit shocks and individual heterogeneity. The left panels demonstrate temporal and accumulated social extractions; right panels demonstrate temporal and accumulated social returns. 
from SO outcomes when the individual heterogeneity $b_{i}$ and property rights share $\sigma_{i}$ are time-variant. In Figure 5, we shuffle $b_{i}$ in each period $t$ and present the simulation results in the top panels; we shuffle $\sigma_{i}$ in each period and present the simulation results in the middle panels; in the bottom panels, both $b_{i}$ and $\sigma_{i}$ are shuffled. The results demonstrate higher volatility in social return under the DRAM. However, the volatility is so tiny that the DRAM allocation still tracks SO very closely.

Lastly, we adjust the magnitude of individual heterogeneity and temporal shocks. In the previous simulations, the upper bound of each random variable is 1 , only one-tenth of the preference parameter $a$. One might expect that the allocation under DRAM will deviate from $\mathrm{SO}$ if the random components exert greater influence on agents' returns. In the following exercise, on top of the time-variant individual heterogeneity and property rights share, we augment the two random variables $b_{i}$ and $\zeta_{t}$ to check if the DRAM still outperforms the classic market. Note that when the negative shock is large, the normalized social return could be negative.

The simulation results are presented in Figure 6. As the augmenting factor increases, the DRAM allocation deviates further from SO. However, as we noticed in the bottom panel, even when $b_{i}$ and $\zeta_{t}$ are augmented by a factor of 5 , the DRAM still results in an allocation that is closer to SO than the market allocation. As shown in the right panels, the DRAM always generates an allocation with temporal return fluctuating around the social optimum, while the market leads to an allocation with a declining return over time.

In sum, the simulation results confirm that the DRAM outperforms the standard property rights market in an environment with significant time-variant individual heterogeneity, temporal shocks, and randomly distributed property rights. With the quadratic return functions, as proved in Lemma 1, there is always a majority of agents whose total profits are concave to the resource allocation $S_{t}$ in each period. Those individuals prefer a dynamic resource allocation that yields the same marginal profit in each period. Although the most preferred allocation might be different across individuals, the concavity of the profit functions results in allocations that generate an approximately equalized marginal return among the agents. Therefore, the DRAM still tracks the social optimum even in a complex environment. 


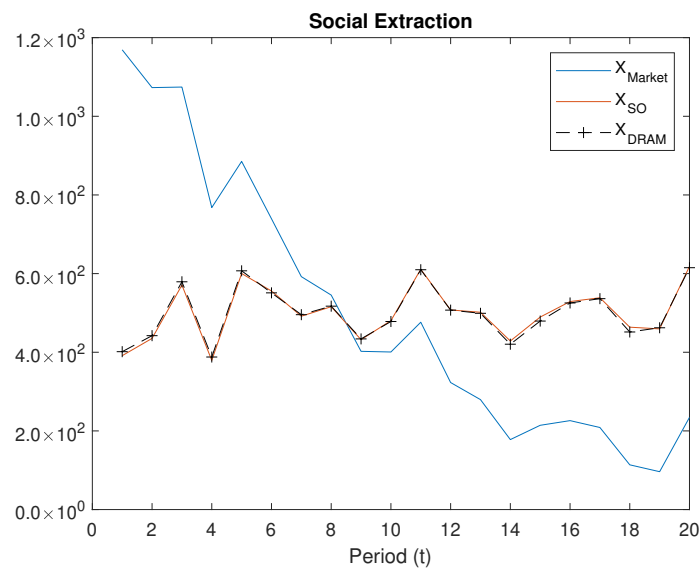

(a) Time-variant $b_{i}$

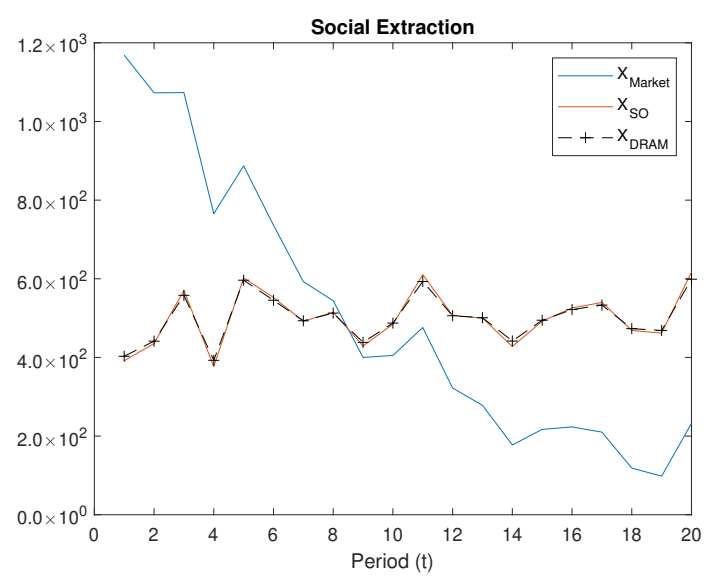

(c) Time-variant $\sigma_{i}$

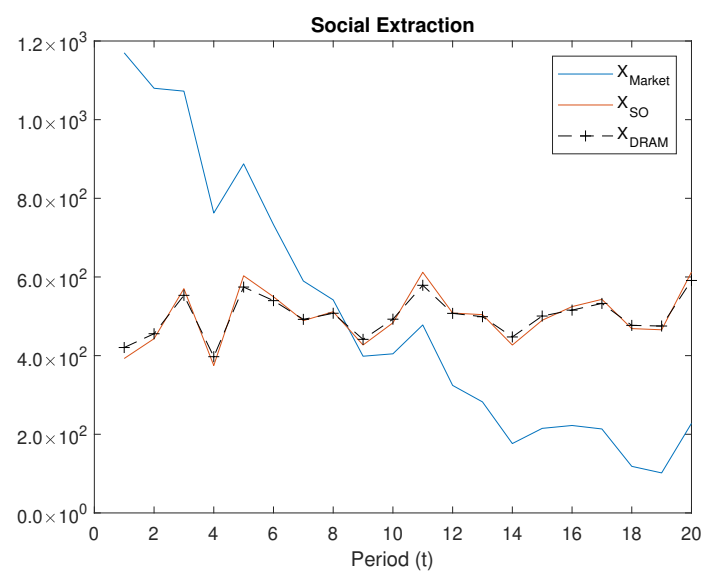

(e) Time-variant $b_{i}$ and $\sigma_{i}$

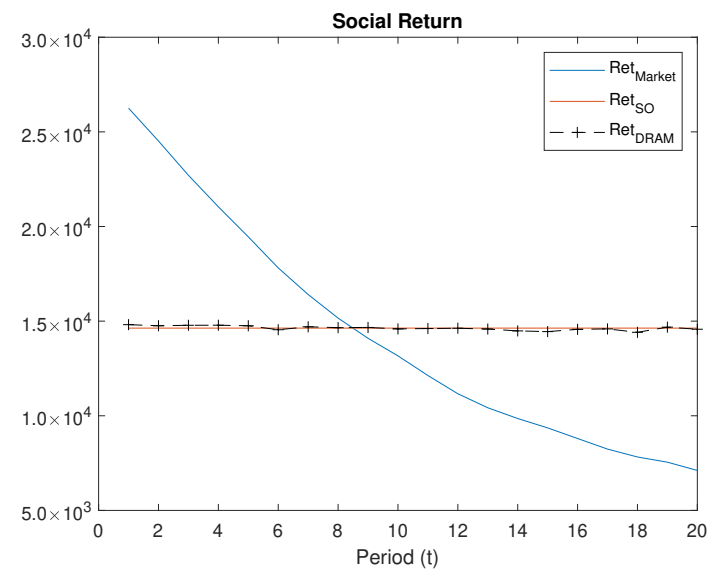

(b) Time-variant $b_{i}$

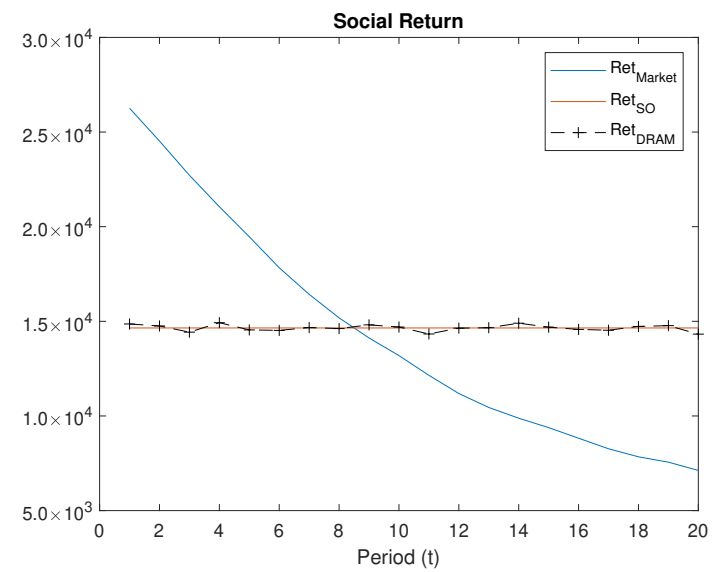

(d) Time-variant $\sigma_{i}$

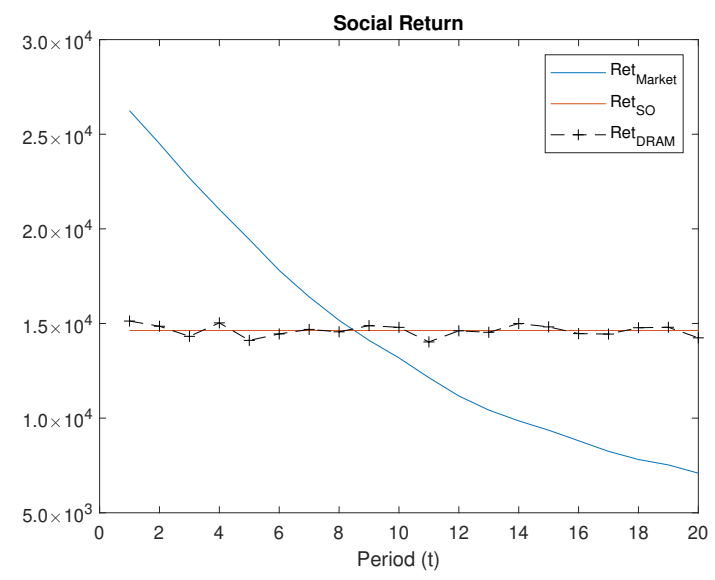

(f) Time-variant $b_{i}$ and $\sigma_{i}$

Figure 5: General Environment, Time-variant Individual Heterogeneity

Note: This figure compares the DRAM, SO and property rights market allocations over 20 periods in a general environment with shuffled individual heterogeneity $b_{i}$ and property rights assignment $\sigma_{i}$. The top panels demonstrate temporal social extractions and returns with time-variant $b_{i}$ only; middle panels demonstrate temporal social extractions and returns with time-variant $\sigma_{i}$ only; bottom panels demonstrate temporal social extractions and returns with both time-variant $b_{i}$ and $\sigma_{i}$. 


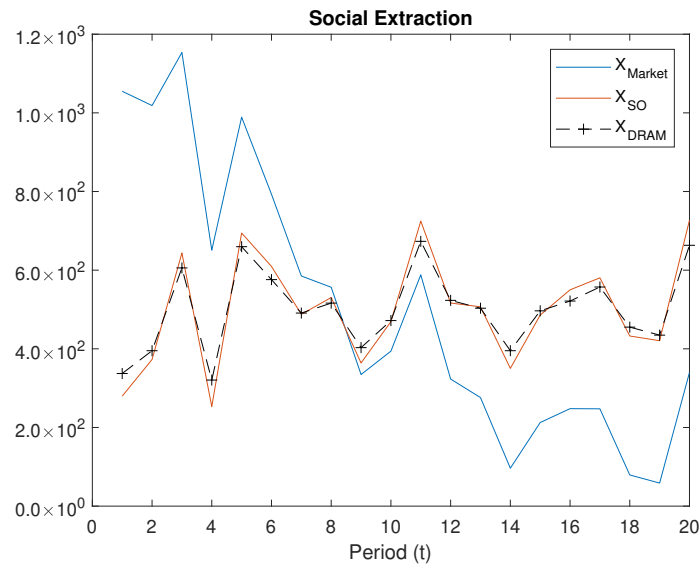

(a) Augmenting factor $=2$

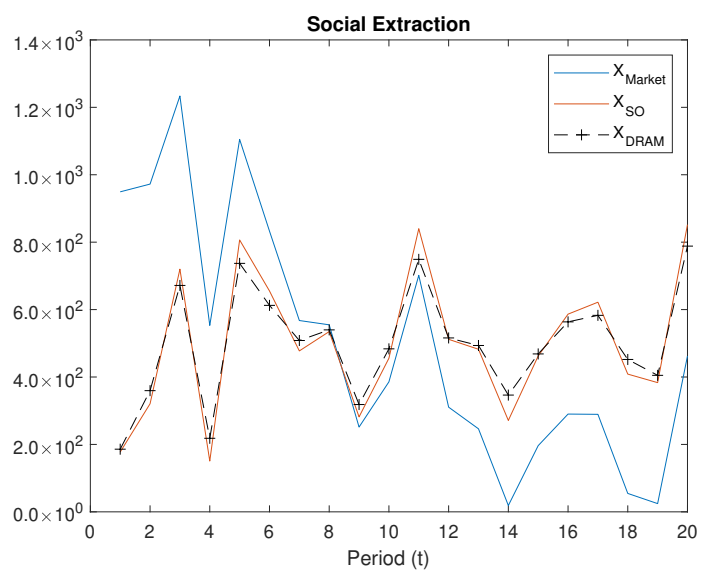

(c) Augmenting factor $=3$

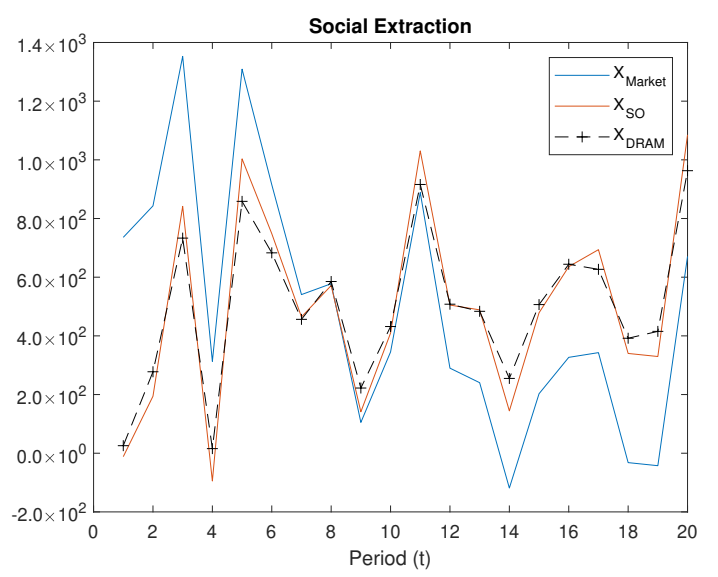

(e) Augmenting factor $=5$

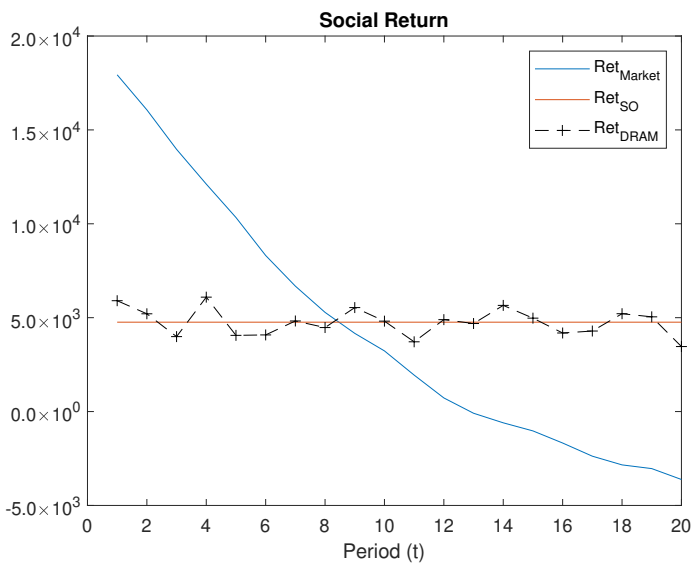

(b) Augmenting factor $=2$

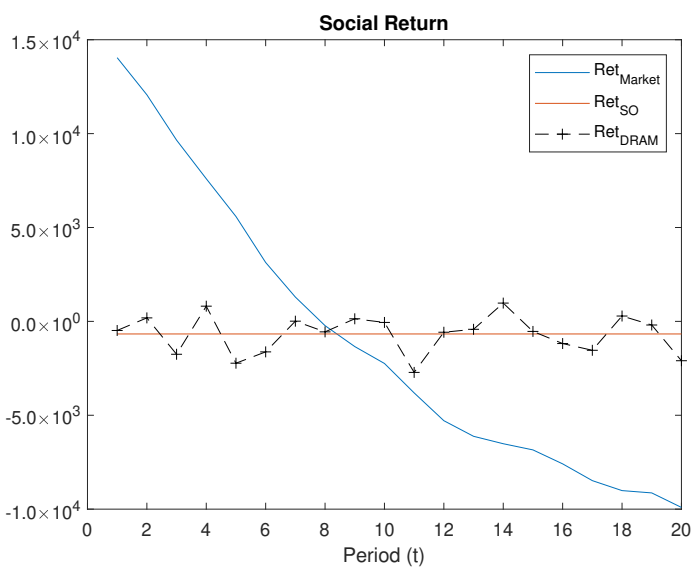

(d) Augmenting factor $=3$

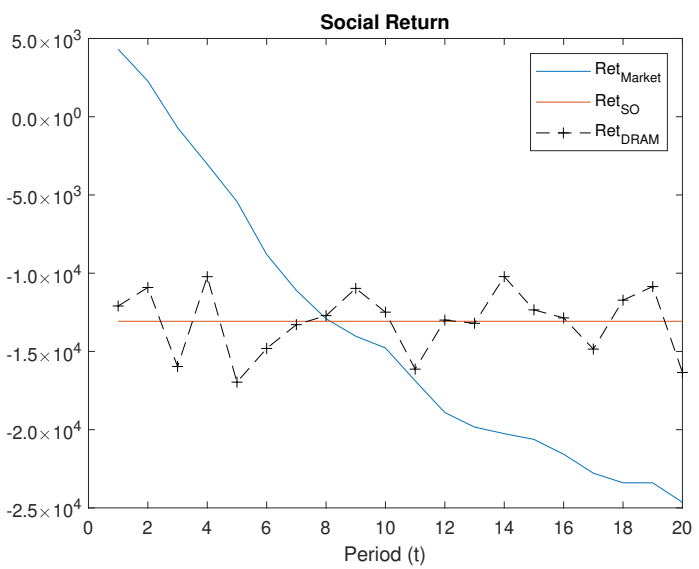

(f) Augmenting factor $=5$

Figure 6: General Environment, Augmented Individual Heterogeneity

Note: This figure compares the DRAM, SO and property rights market allocations over 20 periods in a general environment with augmented individual heterogeneity and profit shocks. The augmenting factor is 2 in top panels, 3 in middle panels and 5 in bottom panels. Sub-figures on the left demonstrate temporal social extractions and sub-figures on the right demonstrate temporal social returns. 
Before the end of the discussion, we note that although the quadratic return functions are necessary for Lemma 1, the result that a majority of agents have concave preference over the aggregate resource allocation $S_{t}$ is still likely to hold even with arbitrary return functions. We have shown that $\sum_{i} u_{i}^{\prime \prime}\left(S_{t}\right)=K_{t}^{\prime}\left(S_{t}\right)<0$. As long as the distribution of individual heterogeneity is not too skewed, the median agent is likely to have a concave preference similar to the "average" agent. Therefore, the DRAM still generates more efficient resource allocation than the property rights market in the general environment.

\section{Conclusion}

Creating property rights for the stock is essential to the CPR valuation problem (Smith, 1977). Well-defined property rights and competitive resource markets resolve the quantity externality that has long been considered as the cause of "the tragedy of the commons" (Garrett, 1968). However, the recent literature has shown that the single price resulted from the property rights market could not fully account for the heterogeneity in the stock value caused by other production externalities. In this paper, we investigate the case with cost externality. If the cost of extraction increases with resource depletion, the stock value declines over time, incentivizing resource users to exercise their extraction rights earlier. The crowded extraction in early periods and decreasing returns to scale can cause a substantial loss of social efficiency.

We propose a dynamic resource allocation mechanism to resolve this inefficiency. The DRAM aggregates individual preferences over total resource allocation over time and implements an optimal allocation plan that puts a binding extraction cap in each period. We develop a theoretical framework to lay out the individual optimization problem over the aggregate resource allocation. The model solution implies that the DRAM can implement the socially optimal allocation if the agents are homogeneous or their preferences are time-consistent.

We further relax the restrictions on the environment and simulate the DRAM allocations in a general environment with individual heterogeneity, temporal profit 
shocks, and random assignment of property rights. The simulated outcomes confirm that the DRAM outperforms the property rights market even in a non-stationary environment. Since most agents exhibit a concave preference over the resource allocation in each period, the DRAM consistently results in an allocation that tracks social optimum more closely than the property rights market.

Coordinating extraction effort has been found to improve the efficiency of allocating scarce resources such as groundwater, oil, fishery, etc. (Wiggins and Libecap, 1985; Costello and Deacon, 2007; Ostrom, 2010; Zhou and Segerson, 2016). This paper adds new insights to this approach as it proves that even in a non-cooperative setting, coordination can be achieved through a majority decision. Therefore, the DRAM has an advantage over the existing cooperatives as it easily aggregates preferences among a large population while the latter might experience coordination failure or incur substantial bargaining costs facing a huge group size.

\section{References}

Anderson, T, OR Burt, and DT Fractor, "Privatizing groundwater basins: a model and its application: in Water Rights, Scarce Resource Allocation, Bureaucracy, and the Environment, by TL Anderson," Pacific Institute for Policy Research, San Francisco, 1983, 348.

Bernard, Mark, Anna Dreber, Pontus Strimling, and Kimmo Eriksson, "The subgroup problem: When can binding voting on extractions from a common pool resource overcome the tragedy of the commons?," Journal of Economic Behavior \& Organization, 2013, 91, 122-130.

Bisack, Kathryn D and Jon G Sutinen, "A New Zealand ITQ fishery with an in-season stock externality," Marine Resource Economics, 2006, 21 (3), 231-249.

Boyce, John R, "Individual transferable quotas and production externalities in a fishery," Natural Resource Modeling, 1992, 6 (4), 385-408. 
Boylan, Richard, John Ledyard, Arthur Lupia, R McKelvey, and Peter Ordeshook, "Political competition in a model of economic growth: an experimental study," Laboratory research in political economy, 1991, pp. 33-68.

Boylan, Richard T, John Ledyard, and Richard D McKelvey, "Political competition in a model of economic growth: Some theoretical results," Economic Theory, 1996, 7 (2), 191-205.

Cancino, Jose P, Hirotsugu Uchida, and James E Wilen, "TURFs and ITQs: collective vs. individual decision making," Marine Resource Economics, 2007, 22 (4), 391-406.

Costello, Christopher and Robert Deacon, "The efficiency gains from fully delineating rights in an ITQ fishery," Marine Resource Economics, 2007, 22 (4), 347-361.

Deacon, Robert $\mathbf{T}$ et al., "Fishery Management by Harvester Cooperatives," Review of Environmental Economics and Policy, 2012, 6 (2), 258-277.

Fell, Harrison, "Ex-vessel pricing and IFQs: A strategic approach," Marine Resource Economics, 2009, 24 (4), 311-328.

Gardner, Roy, Michael R Moore, and James M Walker, "Governing a groundwater commons: a strategic and laboratory analysis of western water law," Economic Inquiry, 1997, 35 (2), 218-234.

Garrett, Hardin, "The tragedy of the commons," Science, 1968, 162 (3859), 12431248.

Gisser, Micha, "Groundwater: focusing on the real issue," Journal of Political Economy, 1983, 91 (6), 1001-1027.

Grafton, R Quentin, Ragnar Arnason, Trond Bjørndal, David Campbell, Harry F Campbell, Colin W Clark, Robin Connor, Diane P Dupont, Rögnvaldur Hannesson, Ray Hilborn et al., "Incentive-based approaches to sustainable fisheries," Canadian Journal of Fisheries and Aquatic Sciences, 2006, 63 (3), 699-710. 
Hahn, Robert D and Roger G Noll, "Designing a market for tradable emissions permits," in W. Magat, ed., Reform of Environmental Regulation, Cambridge: Ballinger, 1982, pp. 119-146.

Heintzelman, Martin D, Stephen W Salant, and Stephan Schott, "Putting free-riding to work: a partnership solution to the common-property problem," Journal of Environmental Economics and Management, 2009, 57 (3), 309-320.

Holland, Daniel S, "Collective rights-based fishery management: a path to ecosystem-based fishery management," Annual Review of Resource Economics, 2018, 10, 469-485.

Huang, Ling and Martin D Smith, "The dynamic efficiency costs of common-pool resource exploitation," American Economic Review, 2014, 104 (12), 4071-4103.

Khezr, Peyman and Ian A MacKenzie, "Consignment auctions," Journal of Environmental Economics and Management, 2018, 87, 42-51.

Moxnes, Erling, "Not only the tragedy of the commons: misperceptions of bioeconomics," Management science, 1998, 44 (9), 1234-1248.

_ , "Overexploitation of renewable resources: The role of misperceptions," Journal of Economic Behavior \& Organization, 1998, 37 (1), 107-127.

Negri, Donald H, "The common property aquifer as a differential game," Water Resources Research, 1989, 25 (1), 9-15.

Ostrom, Elinor, Governing the commons: The evolution of institutions for collective action, Cambridge university press, 1990.

_ , "Beyond markets and states: polycentric governance of complex economic systems," American economic review, 2010, 100 (3), 641-72.

_, Roy Gardner, James Walker, James M Walker, and Jimmy Walker, Rules, games, and common-pool resources, University of Michigan Press, 1994.

Ovando, Daniel A, Robert T Deacon, Sarah E Lester, Christopher Costello, Tonya Van Leuvan, Karlynn McIlwain, C Kent Strauss, 
Michael Arbuckle, Rod Fujita, Stefan Gelcich et al., "Conservation incentives and collective choices in cooperative fisheries," Marine Policy, 2013, 37, 132-140.

Provencher, Bill and Oscar Burt, "The externalities associated with the common property exploitation of groundwater," Journal of Environmental Economics and Management, 1993, 24 (2), 139-158.

Richter, Andries, Daan van Soest, and Johan Grasman, "Contagious cooperation, temptation, and ecosystem collapse," Journal of Environmental Economics and Management, 2013, 66 (1), 141-158.

Schott, Stephan, Neil J Buckley, Stuart Mestelman, and R Andrew Muller, "Output sharing in partnerships as a common pool resource management instrument," Environmental and Resource Economics, 2007, 37 (4), 697-711.

Smith, Vernon L, "Water deeds: a proposed solution to the water valuation problem," Arizona Review, 1977, 26 (1).

Valcu, Adriana and Quinn Weninger, "Markov-Perfect rent dissipation in rightsbased fisheries," Marine Resource Economics, 2013, 28 (2), 111-131.

Walker, James M, Roy Gardner, Andrew Herr, and Elinor Ostrom, "Collective choice in the commons: Experimental results on proposed allocation rules and votes," The Economic Journal, 2000, 110 (460), 212-234.

Wiggins, Steven N and Gary D Libecap, "Oil field unitization: contractual failure in the presence of imperfect information," The American Economic Review, 1985,75 (3), 368-385.

Zhou, Rong and Kathleen Segerson, "Individual vs. collective approaches to fisheries management," Marine Resource Economics, 2016, 31 (2), 165-192. 


\section{Appendices}

\section{A Additional Tables and Figures}

\begin{tabular}{ccc}
\multicolumn{3}{c}{ Table A.1: Parameter Values in Simulation } \\
\hline Parameter & Variable type & Value (range) \\
\hline \hline$N$ & constant & 100 \\
$T$ & constant & 20 \\
$Q$ & constant & 10000 \\
$\mu_{i j}$ & constant & {$[1,4]$} \\
$a$ & constant & 10 \\
$k$ & constant & 0.001 \\
$c_{i}$ & constant & $120 \mu_{i j}$ \\
$b_{i}$ & random & $U(0,1)$ \\
$\zeta_{t}$ & random & $U(0,1)$ \\
\hline
\end{tabular}

\section{B Proofs and Other Technical Details}

\section{B.1 Proof of Proposition 1}

From equation (10), agent $i$ 's marginal extraction cost in period $t, k\left(D_{t}^{M}+\frac{X_{t}^{M}}{2}+\frac{x_{i t}^{M}}{2}\right)$, is always smaller than any agent $j$ 's marginal extraction cost in period $t+1$ since

$$
D_{t}^{M}+\frac{X_{t}^{M}}{2}+\frac{x_{i t}^{M}}{2}<D_{t}^{M}+\frac{X_{t}^{M}}{2}+\frac{X_{t}^{M}}{2}=X_{t+1,0}^{M} \leq X_{t+1,0}^{M}+\frac{X_{t+1}^{M}}{2}+\frac{x_{j, t+1}^{M}}{2} .
$$

As $p^{M}$ is constant across time, according to equation (10), we have

$$
f_{i t}^{\prime}\left(x_{i t}^{M}\right)<f_{j s}^{\prime}\left(x_{j s}^{M}\right) \forall s>t \text { and } \forall i, j
$$

Therefore, $\min _{j} f_{j s}^{\prime}\left(x_{j s}^{M}\right)>\max _{i} f_{i t}^{\prime}\left(x_{i t}^{M}\right)$ for all $s>t$. 
Recall the socially optimal allocation represented by equation (3). Denote the value of $f_{i t}^{\prime}\left(x_{i t}^{S O}\right)$ by a constant $c$. There must exists a period $t$ such that $c \in$ $\left[\min _{i} f_{i t}^{\prime}\left(x_{i t}^{M}\right), \max _{i} f_{i t}^{\prime}\left(x_{i t}^{M}\right)\right]$. Otherwise, if $c>\max _{i} f_{i T}^{\prime}\left(x_{i T}^{M}\right)$, we have $f_{i t}^{\prime}\left(x_{i t}^{M}\right)<c$ and thus $x_{i t}^{M}>x_{i t}^{S O}$ for all $i$ and $t$. This is a contradiction to the binding resource constraint under the two equilibria $\sum_{i, t} x_{i t}^{S O}=\sum_{i, t} x_{i t}^{M}=Q$. A similar contradiction arises when $c<\min _{i} f_{i 1}^{\prime}\left(x_{i 1}^{M}\right)$.

Given the period $t$ that $c \in\left[\min _{i} f_{i t}^{\prime}\left(x_{i t}^{M}\right), \max _{i} f_{i t}^{\prime}\left(x_{i t}^{M}\right)\right]$, for all $s<t, f_{i s}^{\prime}\left(x_{i s}^{M}\right)<c$ since $\max _{i} f_{i s}^{\prime}\left(x_{i s}^{M}\right)<\min _{i} f_{i t}^{\prime}\left(x_{i t}^{M}\right)$, and similarly, for all $s>t, f_{i s}^{\prime}\left(x_{i s}^{M}\right)>c$ since $\min _{i} f_{i s}^{\prime}\left(x_{i s}^{M}\right)>\max _{i} f_{i t}^{\prime}\left(x_{i t}^{M}\right)$. As $f(\cdot)$ is concave, that implies $x_{i s}^{M}>x_{i s}^{S O}$ for $s<t$ and $x_{i s}^{M}<x_{i s}^{S O}$ for $s>t$. Therefore $X_{s}^{M}>X_{s}^{S O}$ for $s<t$ and $X_{s}^{M}<X_{s}^{S O}$ for $s>t$.

For $s=t$, it could be either $X_{t}^{M}<X_{t}^{S O}$ or $X_{t}^{M} \geq X_{t}^{S O}$. If $X_{t}^{M} \geq X_{t}^{S O}$, we have establish the fact that for all $s \leq t, X_{s}^{M} \geq X_{s}^{S O}$ and for all $s>t, X_{s}^{M}<X_{s}^{S O}$. If $X_{t}^{M}<X_{t}^{S O}$, for all $s \leq t-1, X_{s}^{M} \geq X_{s}^{S O}$ and for all $s>t-1, X_{s}^{M}<X_{s}^{S O}$. Moreover, the threshold $t$ in the first case or $t-1$ in the second case must be within the interval $[1, T)$, otherwise the binding resource constraint will be violated.

\section{B.2 Proof of Lemma 1}

We prove by contradiction. If there does not exist a majority set satisfying the condition, there must exists a majority set $J$ such that $u_{j_{m}}^{\prime \prime}\left(S_{t}\right) \geq 0$ for all $j_{m} \in J$.

Since $K^{\prime}\left(S_{t}\right)<0,2 \sigma_{j_{m}}-x_{j_{m}}^{\prime}\left(S_{t}\right) \leq 0$ for all $j_{m}$. Hence $\sum_{j_{m}}\left[2 \sigma_{j_{m}}-x_{j_{m}}^{\prime}\left(S_{t}\right)\right] \leq 0$. However, $\sum_{j_{m}} 2 \sigma_{j_{m}}=2 \sum_{j_{m}} \sigma_{j_{m}}>1$ by the definition of majority. Meanwhile, according to equations (26), $x_{i}^{\prime}\left(S_{t}\right)>0$ and $\sum_{j_{m}} x_{j_{m}}^{\prime}\left(S_{t}\right)<1$. That leads to $\sum_{j_{m}}\left[2 \sigma_{j_{m}}-x_{j_{m}}^{\prime}\left(S_{t}\right)\right]>0$. Contradiction! 